\title{
Removal of cobalt(II), copper(II), and nickel(II) ions from aqueous solutions using phthalate-functionalized sugarcane bagasse: Mono- and multicomponent adsorption in batch mode
}

\author{
Stela Nhandeyara do Carmo Ramos, Amália Luísa Pedrosa Xavier, Filipe Simões Teodoro, \\ Laurent Frédéric Gil, Leandro Vinícius Alves Gurgel*
}

Group of Physical Organic Chemistry (GPOC), Department of Chemistry, Institute of Biological and Exact Sciences (ICEB), Federal University of Ouro Preto, Campus Morro do Cruzeiro, Bauxita 35400-000 Ouro Preto, Minas Gerais, Brazil

\section{A R T I C L E I N F O}

\section{Article history:}

Received 3 July 2015

Received in revised form 16 October 2015

Accepted 16 October 2015

Available online 18 November 2015

\section{Keywords:}

Sugarcane bagasse

Phthalic anhydride

Adsorption

Metal ion

Desorption

\begin{abstract}
A B S T R A C T
This study describes, in detail, the chemical modification of sugarcane bagasse with phthalic anhydride to produce a carboxylate-functionalized sugarcane bagasse (SPA). The optimized modification conditions yielded SPA with a percent weight gain of $77.08 \%$ and an amount of carboxylic acid groups of 4.76 $\mathrm{mmol} / \mathrm{g}$. The SPA was characterized by PZC, FTIR, elemental analysis, TGA, and SEM-EDX. An SPA adsorbent was used to remove $\mathrm{Co}^{2+}, \mathrm{Cu}^{2+}$, and $\mathrm{Ni}^{2+}$ from aqueous solution in mono- and multicomponent systems in batch mode. The adsorption kinetics followed a pseudo-second-order model. The adsorption rate constants assumed the following order: $k_{2, \mathrm{Co}^{2+}}>k_{2, \mathrm{Ni}^{2+}}>k_{2, \mathrm{Cu}^{2+}}$. Four mono- and multicomponent isotherm models were used to model the adsorption data. Monocomponent data were well described by the Langmuir model, whereas bicomponent data were well described by the modified extended Langmuir and $P$-Factor models. The maximum adsorption capacities $\left(Q_{\text {max,mono }}\right.$ ) for the Langmuir model were $0.561,0.935$, and $0.932 \mathrm{mmol} / \mathrm{g}$ for $\mathrm{Co}^{2+}, \mathrm{Cu}^{2+}$, and $\mathrm{Ni}^{2+}$, respectively. Adsorption in bicomponent systems revealed that $\mathrm{Cu}^{2+}$ suppressed the adsorption of $\mathrm{Co}^{2+}$ and $\mathrm{Ni}^{2+}$, whereas $\mathrm{Ni}^{2+}$ suppressed the adsorption of $\mathrm{Co}^{2+}$. Desorption studies revealed that the SPA adsorbent could be fully desorbed with a $1 \mathrm{~mol} / \mathrm{L} \mathrm{HNO}$ solution.
\end{abstract}

(C) 2015 Elsevier B.V. All rights reserved.

\section{Introduction}

The pollution of water by heavy metals is becoming a serious global problem, as they are toxic, non-degradable, and bioaccumulative (Boamah et al., 2015; Fu and Wang, 2011; Salman et al., 2015). The fast development of industries such as metal plating, mining, fertilizers, tanneries, batteries, paper, pesticides, electronics, petrochemical, textile, among others has contributed to an increase in the concentration of toxic metals in wastewaters, which are directly or indirectly discharged into the environment, mainly in developing countries (Barakat, 2011; Fu and Wang, 2011; Kazemipour et al., 2008). Some toxic metals of particular concern in the treatment of industrial wastewaters and acid mine drainage include arsenic(III) and (V), cadmium(II), chromium(III) and (VI), cobalt(II), copper(II), lead(II), mercury(II), manganese(II), nickel(II), and zinc(II) (Barakat, 2011; Dumrul et al., 2011; Fu and Wang, 2011; Kursunlu et al., 2009;

\footnotetext{
* Corresponding author. Tel.: +55 313559 1744; fax: + 553135591707.

E-mail addresses: legurgel@iceb.ufop.br, legurgel@yahoo.com.br (L.V.A. Gurgel).
}

Sheoran and Sheoran, 2006). Toxic metals are thought to biomagnify, and biomagnification is one of the most significant reasons for which metals are deemed harmful to the environment and living organisms (Boamah et al., 2015; Fu and Wang, 2011). Heavy metals are also known to be carcinogenic and their adverse effects in humans were well documented by Klaassen (2008).

Nowadays, the regulations used to control the concentration of toxic metals in industrial effluents are becoming more and more stringent, as the adverse effects of toxic metals are becoming more well-known. Therefore, toxic metals must be removed from wastewaters and acid mine drains in order to protect the environment and living organisms (Fu and Wang, 2011; Sheoran and Sheoran, 2006). According to Fu and Wang (2011) as well as Barakat (2011), various methods are being used to remove toxic metals. They include chemical precipitation, ion-exchange, adsorption, ultra- and nanofiltration, reverse osmosis, electrochemical, and electrodialysis techniques. Among these methods, adsorption has been recognized as an effective and economic method to treat wastewaters containing toxic metals. It offers flexibility in design and operation, as the adsorption process can be operated in batch 
or semicontinuous (fixed-bed column) modes (Fu and Wang, 2011). In general, adsorption also produces high-quality treated effluents and, because adsorption is often reversible, the adsorbents can be regenerated through a suitable desorption process and reused, and the adsorbate can also be recovered (Fu and Wang, 2011). When the adsorbent is reused and the adsorbate can be recovered, the adsorption is more economically favorable. Particularly, the use of low-cost adsorbents, derived from agricultural crop residues, natural materials, industrial by-products, or modified lignocellulosic materials, with a metal ion-binding capacity has recently been pursued, as it makes the adsorption process more suitable (Barakat, 2011). Among these bioadsorbents, sugarcane bagasse (SB) is a promising alternative, as it is largely available in countries such as Brazil, China, and India (Ferreira et al., 2015; Yu et al., 2015). According to Rocha et al. (2015), SB from different Brazilian regions is composed, on average, of cellulose $(42.19 \pm 1.93 \%)$, hemicelluloses $(27.60 \pm 0.88 \%)$, lignin $(21.56 \pm 1.67 \%)$, inorganics $(5.63 \pm 2.31 \%)$, and extractives $(2.84 \pm 1.22 \%)$.

Cellulose, hemicelluloses, and lignin have different types of hydroxyl groups that can be modified with specific organic ligands, exhibiting a metal ion-binding capacity. Several chemical methods have been used and reported to modify lignocellulosic materials to improve their metal ion-binding capacity, such as esterification, etherification, halogenation followed by functionalization with organic ligands based on amine and sulfur compounds, oxidation, and chemical grafting modification (Sun, 2010; Wan Ngah and Hanafiah, 2008). In addition to the enhanced metal ionbinding capacity provided by chemical modification, certain types of organic ligands can provide modified adsorbent materials with greater selectivity for the removal of specific metal ions by using oxygen, amine, sulfur, among other electron-donor atoms or groups that exhibit different affinities to metal ions (Dąbrowski et al., 2004; Hancock and Martell, 1989).

This study aimed to produce an adsorbent based on SB with a metal ion-binding capacity through an esterification reaction between phthalic anhydride (PA) and hydroxyl groups of SB. PA is a commercial and stable reagent. It is use to introduce a metal ion-binding capacity into SB, and it is suitable because PA is a cheaper reagent than those often used for this purpose (Sun, 2010). In this study, the chemical modification of SB with PA was extensively studied and optimized. The produced adsorbent material was used to study the adsorption of $\mathrm{Co}^{2+}, \mathrm{Cu}^{2+}$, and $\mathrm{Ni}^{2+}$ from spiked mono- and bicomponent aqueous solutions. The influences of contact time, $\mathrm{pH}$ of the solution, and initial metal-ion concentration on adsorption were also studied in detail. A suitable desorption process and the reuse of the spent adsorbent were also evaluated.

\section{Material and methods}

\subsection{Material}

$\mathrm{CoCl}_{2} \cdot 6 \mathrm{H}_{2} \mathrm{O}, \mathrm{CuSO}_{4} \cdot 5 \mathrm{H}_{2} \mathrm{O}$, monochlroacetic acid (99\%), and isopropanol were purchased from Synth (Brazil). Phthalic anhydride (99\%) (cat no. 125733) was purchased from Sigma-Aldrich (Brazil). $\mathrm{NiCl}_{2} \cdot 6 \mathrm{H}_{2} \mathrm{O}$, glacial acetic acid $(99.5 \%), \mathrm{NaOH}, \mathrm{HCl}(37 \% \mathrm{w} / \mathrm{w})$, acetone, and pyridine (Py) were purchased from Vetec (Brazil). Quantitative filter papers (blue ribbon, JP-41, cat no. 3509-1, $12.5 \mathrm{~cm}$ diameter, ash content of $0.00009 \mathrm{~g}$, and grammage of $80 \mathrm{~g} / \mathrm{cm}^{2}$ ) were purchased from JProlab (Brazil). Py was refluxed in a $2 \mathrm{~L}$ round-bottomed flask with $\mathrm{NaOH}$ pellets for $12 \mathrm{~h}$, distilled, and stored in flat-bottomed flasks containing $\mathrm{NaOH}$ pellets before use. All metal-ion solutions were prepared using deionized water (Millipore, model Milli- $Q^{\circledR}$ Simplicity ${ }^{\circledR}$ ). SB stalks were collected at Ouro Preto, Minas Gerais, Brazil. SB stalks were prepared for chem- ical modification following the methodology proposed by Ramos et al. (2015).

\subsection{Modification of sugarcane bagasse with phthalic anhydride}

The esterification reaction between hydroxyl groups of SB and PA was studied as a function of reaction time and amount of PA.

\subsubsection{Modification of sugarcane bagasse as a function of the amount of phthalic anhydride}

SB (1.0 g), PA (2.0, 4.0, 6.0, or $8.0 \mathrm{~g})$, and anhydrous Py (15 mL) were added to a $100 \mathrm{~mL}$ round-bottomed flask to give a solid-toliquid ratio of 1:15 (w/v). A reflux condenser with a drying tube filled with anhydrous calcium chloride was attached to the flask. The suspension was heated at $100^{\circ} \mathrm{C}$ in an oil bath placed on a heating plate (Corning ${ }^{\circledR}$, model PC-420D) under constant magnetic stirring at $300 \mathrm{rpm}$ for $3 \mathrm{~h}$. At the end of the reaction, the modified SB was left to cool for $30 \mathrm{~min}$ and then transferred to a $250 \mathrm{~mL}$ beaker containing $125 \mathrm{~mL}$ of isopropanol. It was magnetically stirred for $30 \mathrm{~min}$, after which it was transferred to a $150 \mathrm{~mL}$ glass Buchner funnel (disc diameter of $60 \mathrm{~mm}$ and porosity of 3). The modified SB was washed with isopropanol twice. Then, the phthalate-modified sugarcane bagasse (SPA) was separated by vacuum filtration and washed sequentially with distilled water $(100 \mathrm{~mL}), 0.01 \mathrm{~mol} / \mathrm{L}$ aqueous $\mathrm{HCl}$ solution $(100 \mathrm{~mL})$, distilled water $(100 \mathrm{~mL})$, and isopropanol $(50 \mathrm{~mL})$ (Ko et al., 2010). The SPA was then dried in an oven at $95^{\circ} \mathrm{C}$ for $2.5 \mathrm{~h}$, placed in a desiccator to cool, and weighed. The values of percent weight gain ( $p w g)$ and amount of carboxylic acid groups $\left(n_{\mathrm{COOH}}\right)$ were determined.

\subsubsection{Modification of sugarcane bagasse as a function of reaction time}

$\mathrm{SB}(1.0 \mathrm{~g}), \mathrm{PA}(6.0$ or $8.0 \mathrm{~g})$, and anhydrous $\mathrm{Py}(15 \mathrm{~mL})$ were added to a $100 \mathrm{~mL}$ round-bottomed flask to give a solid-to-liquid ratio of $1: 15(\mathrm{w} / \mathrm{v})$. A reflux condenser with a drying tube filled with anhydrous calcium chloride was attached to the flask. The suspensions were heated at $100^{\circ} \mathrm{C}$ in an oil bath placed on a heating plate (Corning ${ }^{\circledR}$, model PC-420D) under constant magnetic stirring at $300 \mathrm{rpm}$. The reaction times studied for $6.0 \mathrm{~g}$ of PA were 3 and $6 \mathrm{~h}$ and for $8.0 \mathrm{~g}$ they were $1,3,6,12,18$, and $24 \mathrm{~h}$. The purification and characterization of the SPAs followed the procedures described in Section 2.2.1.

\subsection{Characterization of modified sugarcane bagasse with phthalic anhydride}

All samples were previously dried in an oven at $90^{\circ} \mathrm{C}$ for $1 \mathrm{~h}$ and stored in a desiccator before analyses, with the exception of those used for the determination of the percent weight gain.

\subsubsection{Percent weight gain}

The percent weight gain ( $p w g$ ) after esterification of the hydroxyl groups of SB with PA was calculated using Eq. (1):

$\operatorname{pwg}=\left(\frac{w_{\mathrm{SPA}}-w_{\mathrm{SB}}}{w_{\mathrm{SB}}}\right) \times 100$

where $p w g(\%)$ is the percent weight gain, and $w_{\mathrm{SPA}}$ and $w_{\mathrm{SB}}(\mathrm{g})$ are the weights of SPA and SB, respectively.

\subsubsection{Amount of carboxylic acid groups}

The amount of carboxylic acid groups $\left(n_{\mathrm{COOH}}\right)$ released after the esterification of SB with PA was determined by back titration. Two $0.1000 \mathrm{~g}$ samples of SPA were weighed into $250 \mathrm{~mL}$ Erlenmeyer flasks, and $100.0 \mathrm{~mL}$ of standardized aqueous $\mathrm{NaOH}$ solution (10 $\mathrm{mmol} / \mathrm{L}$ ) was added to each flask. The flasks were mechanically stirred $(100 \mathrm{rpm})($ Nova Ética, model $109 / 2)$ for $60 \mathrm{~min}$ at $25^{\circ} \mathrm{C}$. 
Then, the suspensions were filtered using a single filtration (JP-41 filter paper). Three $20.0 \mathrm{~mL}$ aliquots from each flask were titrated with standardized aqueous $\mathrm{HCl}$ solution $(10 \mathrm{mmol} / \mathrm{L}$ ) until the endpoint of phenolphthalein. The $n_{\mathrm{COOH}}$ of SPA was calculated using Eq. (2):

$n_{\mathrm{COOH}}=\frac{\left[C_{\mathrm{NaOH}} V_{\mathrm{NaOH}}-5\left(C_{\mathrm{HCl}} V_{\mathrm{HCl}}\right)\right]}{w_{\mathrm{SPA}}}$

where $n_{\mathrm{COOH}}(\mathrm{mmol} / \mathrm{g})$ is the amount of carboxylic acid groups on the SPA surface and $C_{\mathrm{NaOH}}$ and $C_{\mathrm{HCl}}(\mathrm{mmol} / \mathrm{L})$ are the concentrations of $\mathrm{NaOH}$ and $\mathrm{HCl}$ solutions, respectively, $V_{\mathrm{NaOH}}(\mathrm{L})$ is the volume of $\mathrm{NaOH}$ solution and $V_{\mathrm{HCl}}(\mathrm{L})$ is the volume of $\mathrm{HCl}$ solution expended when titrating excess unconsumed $\mathrm{NaOH}$, and $w_{\mathrm{SPA}}(\mathrm{g})$ is the weight of SPA.

\subsubsection{Point of zero charge (PZC)}

Three $0.01 \mathrm{~mol} / \mathrm{L} \mathrm{NaNO}_{3}$ solutions with $\mathrm{pH}$ values of 3,6 , and 11 were prepared by adjusting the $\mathrm{pH}$ of the solutions using $0.1 \mathrm{~mol} / \mathrm{L}$ $\mathrm{HNO}_{3}$ and $\mathrm{NaOH}$ solutions. Different amounts of SPA samples were added to five $125 \mathrm{~mL}$ Erlenmeyer flasks and $20.0 \mathrm{~mL}$ of $\mathrm{NaNO}_{3}$ solution of $\mathrm{pH} 3,6$, or 11 was added to each flask to give suspensions of $0.05,0.1,0.5,1$, and $2 \%(\mathrm{w} / \mathrm{v})$. The flasks were mechanically stirred $(130 \mathrm{rpm})($ Nova Ética, model $109 / 2)$ for $24 \mathrm{~h}$ at $25^{\circ} \mathrm{C}$. Then, the equilibrium $\mathrm{pH}$ value was measured using a $\mathrm{pH}$ meter (Hanna Instruments, model HI 223) to obtain the PZC.

\subsubsection{Fourier-transform infrared spectroscopy (FTIR)}

Samples of SB, SPA, and SPA loaded with $\mathrm{Co}^{2+}, \mathrm{Cu}^{2+}$, and $\mathrm{Ni}^{2+}$ $(1.0 \mathrm{mg})$ were mixed with $100 \mathrm{mg}$ of spectroscopy-grade $\mathrm{KBr}$ and pressed in a hydraulic press at 8 tons for $0.5 \mathrm{~min}$ to obtain $13 \mathrm{~mm}$ $\mathrm{KBr}$ pellets (Pike CrushIR, model 181-1110, Pike Technologies, Canada). The FTIR spectra were recorded on an ABB Bomen MB 3000 FTIR spectrometer (Quebec, Canada) equipped with optics of ZnSe and a DTGS detector set at a resolution of $4 \mathrm{~cm}^{-1}$ from 500 to $4000 \mathrm{~cm}^{-1}$ with 32 scans.

\subsubsection{Energy-dispersive X-ray (EDX) spectroscopy}

Samples of SPA loaded with $\mathrm{Co}^{2+}, \mathrm{Cu}^{2+}$, and $\mathrm{Ni}^{2+}$ were analyzed on a Vega3 SB SEM-EDX spectrometer (Tescan/Oxford Instruments) using a filament voltage of $20 \mathrm{keV}$ and a backscattered electron (BSE) detector. Samples of $100 \mathrm{mg}$ of SPA loaded with metal ions were pressed in a hydraulic press at 8 tons for $1 \mathrm{~min}$ to prepared pellets of $13 \mathrm{~mm}$. Then, they were sputter-coated with carbon in modular high-vacuum coating equipment (Quorum Technologies, model Q150R ES).

\subsection{Adsorption experiments}

Adsorption of $\mathrm{Co}^{2+}, \mathrm{Cu}^{2+}$, and $\mathrm{Ni}^{2+}$ on SPA in a monocomponent system was studied as a function of contact time (kinetics), $\mathrm{pH}$ of the solution, and initial concentration of metal ions (isotherm). Bicomponent adsorption isotherms composed of $\mathrm{CO}^{2+}-\mathrm{Cu}^{2+}, \mathrm{CO}^{2+}-\mathrm{Ni}^{2+}$, and $\mathrm{Cu}^{2+}-\mathrm{Ni}^{2+}$ systems in equimolar concentrations were also studied.

\subsubsection{Adsorption of metal ions on SPA as a function of contact time (kinetics)}

Samples of $100.0 \mathrm{~mL}$ of each metal-ion solution $(0.79 \mathrm{mmol} / \mathrm{L})$, buffered at $\mathrm{pH} 5.5$ for $\mathrm{Cu}^{2+}$ and 5.75 for $\mathrm{Co}^{2+}$ and $\mathrm{Ni}^{2+}(0.05 \mathrm{~mol} / \mathrm{L}$ $\mathrm{CH}_{3} \mathrm{COOH} / \mathrm{CH}_{3} \mathrm{COONa}$ ), were added to $250 \mathrm{~mL}$ Erlenmeyer flasks and pre-thermostated to $25^{\circ} \mathrm{C}$ in a shaker incubator for $1 \mathrm{~h}$ (Tecnal, model TE-424, Piracicaba, SP, Brazil). Then, samples of SPA $(20.0 \mathrm{mg})$ weighed in cylindrical glasses $(1.8 \mathrm{~mm}$ height $\times 2.2 \mathrm{~mm}$ diameter) were added to each Erlenmeyer flask and stirred at $130 \mathrm{rpm}$ for different time intervals. Then, the solids were filtered off using a single filtration (JP-41 filter paper) and the concentration of metal ion at time $t$ was determined by a flame atomic absorption spectrophotometer (FAAS) (Hitachi, model Z-8200) $\left(\lambda_{\mathrm{Co}}=240.7 \mathrm{~mm}, \lambda_{\mathrm{Cu}}=324.8 \mathrm{~mm}\right.$, and $\left.\lambda_{\mathrm{Ni}}=232 \mathrm{~mm}\right)$. The amount of each metal ion adsorbed on SPA at time $t$ was calculated using Eq. (3):

$q_{\mathrm{t}}=\frac{\left[\left(C_{\mathrm{i}}-C_{\mathrm{t}}\right)_{\mathrm{M}^{2+}} V_{\mathrm{M}^{2+}}\right]}{w_{\mathrm{SPA}}}$

where $q_{\mathrm{t}}(\mathrm{mmol} / \mathrm{g})$ is the amount of metal ion $\left(\mathrm{M}^{2+}\right)$ adsorbed per unit weight of SPA at a time $t, V_{\mathrm{M}^{2+}}(\mathrm{L})$ is the volume of metal-ion solution, $C_{\mathrm{i}}$ and $C_{\mathrm{t}}(\mathrm{mmol} / \mathrm{L})$ are the metal-ion solution concentrations at 0 and time $t$, respectively, and $w_{\mathrm{SPA}}(\mathrm{g})$ is the weight of SPA.

\subsubsection{Adsorption of metal ions on SPA as a function of solution $p H$}

Samples of SPA $(20.0 \mathrm{mg}$ ) were directly weighed into $250 \mathrm{~mL}$ Erlenmeyer flasks, and $100.0 \mathrm{~mL}$ of each metal-ion solutions $(0.79 \mathrm{mmol} / \mathrm{L})$ buffered at $\mathrm{pH}$ values from 2.0 to $3.5(0.05 \mathrm{~mol} / \mathrm{L}$ $\left.\mathrm{ClCH}_{2} \mathrm{COOH} / \mathrm{ClCH}_{2} \mathrm{COONa}\right)$ and from 4.0 to $5.75(0.05 \mathrm{~mol} / \mathrm{L}$ $\mathrm{CH}_{3} \mathrm{COOH} / \mathrm{CH}_{3} \mathrm{COONa}$ ) were added. The Erlenmeyer flasks were placed into a pre-thermostated shaker incubator at $25^{\circ} \mathrm{C}$ and stirred at $130 \mathrm{rpm}$ until equilibrium was reached. Then, the solids were filtered off through a single filtration (JP-41 filter paper) and the concentrations of metal ions were determined by FAAS. The maximum $\mathrm{pH}$ value of each metal-ion solution required to avoid the formation of hydrolyzed species and precipitation was calculated using the concentration of each metal-ion solution and the solubility product constant $\left(K_{\mathrm{sp}}\right)$ for $\mathrm{Co}(\mathrm{OH})_{2}\left(5.92 \times 10^{-15}\right)$, $\mathrm{Cu}(\mathrm{OH})_{2}\left(1.8 \times 10^{-20}\right)$, and $\mathrm{Ni}(\mathrm{OH})_{2}\left(5.48 \times 10^{-16}\right)$ (Haynes, 2014).

\subsubsection{Adsorption as a function of the initial metal-ion concentration}

2.4.3.1. Monocomponent isotherms. Samples of SPA (20.0 mg) were directly weighed into $250 \mathrm{~mL}$ Erlenmeyer flasks, and $100.0 \mathrm{~mL}$ of each metal-ion solution, buffered at $\mathrm{pH} 5.5$ for $\mathrm{Cu}^{2+}$ and 5.75 for $\mathrm{Co}^{2+}$ and $\mathrm{Ni}^{2+}\left(0.05 \mathrm{~mol} / \mathrm{L} \mathrm{CH}_{3} \mathrm{COOH} / \mathrm{CH}_{3} \mathrm{COONa}\right)$, with concentrations ranging from 0.05 to $1.12 \mathrm{mmol} / \mathrm{L}$, were added. Further experimental procedures were the same as those described in Sections 2.4.1 and 2.4.2.

2.4.3.2. Bicomponent isotherms. Samples of SPA $(20.0 \mathrm{mg})$ were directly weighed into $250 \mathrm{~mL}$ Erlenmeyer flasks, and $100.0 \mathrm{~mL}$ of the binary equimolar metal-ion solutions, buffered at $\mathrm{pH} 5.5$ ( $0.05 \mathrm{~mol} / \mathrm{L} \mathrm{CH} \mathrm{CH}_{3} \mathrm{COOH} / \mathrm{CH}_{3} \mathrm{COONa}$ ), with concentrations ranging from 0.05 to $1.12 \mathrm{mmol} / \mathrm{L}$ for $\mathrm{Co}^{2+}-\mathrm{Cu}^{2+}, \mathrm{Co}^{2+}-\mathrm{Ni}^{2+}$, and $\mathrm{Cu}^{2+}-\mathrm{Ni}^{2+}$, were added. Further experimental procedures were the same as those described in Sections 2.4.1 and 2.4.2.

\subsection{Desorption experiments}

Samples of SPA (100 mg) were directly weighed into $250 \mathrm{~mL}$ Erlenmeyer flasks, and $100.0 \mathrm{~mL}$ of each metal-ion solution $\left(3.15 \mathrm{mmol} / \mathrm{L}\right.$ for $\mathrm{Co}^{2+}, \mathrm{Cu}^{2+}$, and $\left.\mathrm{Ni}^{2+}\right)$ buffered at $\mathrm{pH} 5.5(0.05 \mathrm{~mol} / \mathrm{L}$ $\mathrm{CH}_{3} \mathrm{COOH} / \mathrm{CH}_{3} \mathrm{COONa}$ ) was added. The flasks were stirred in a pre-thermostated shaker incubator at $25^{\circ} \mathrm{C}$ and $130 \mathrm{rpm}$ for $180 \mathrm{~min}$, using the optimal experimental parameters determined from the respective adsorption studies for $\mathrm{Co}^{2+}, \mathrm{Cu}^{2+}$, and $\mathrm{Ni}^{2+}$. Then, the solids were filtered off through a single filtration step, washed with an excess of deionized water, dried in an oven at $60^{\circ} \mathrm{C}$ for $12 \mathrm{~h}$, and stored in a desiccator. Dried samples of SPA (20.0 mg) loaded with each metal ion were directly weighed into $250 \mathrm{~mL}$ Erlenmeyer flasks, and $20.0 \mathrm{~mL}$ of $1.0 \mathrm{~mol} / \mathrm{L} \mathrm{HNO}_{3}$ was added. The flasks were placed into a pre-thermostated shaker incubator at $25^{\circ} \mathrm{C}$ and $130 \mathrm{rpm}$ for $5 \mathrm{~min}$. Further experimental procedures were 
(a)<smiles>CC(C)OC(=O)c1ccccc1C(=O)O</smiles>

(b) anhydride (PA)<smiles>COC(=O)c1ccccc1C(=O)O</smiles><smiles></smiles>

(c)<smiles>[Y2][Y4](=O)C(=O)c1ccccc1C(=O)OCC</smiles><smiles>CCOC(=O)c1ccccc1C(=O)O</smiles>

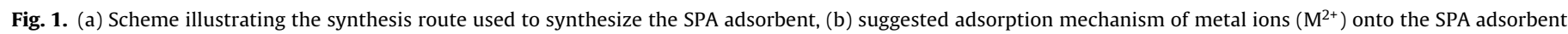
$\left[\mathrm{M}=\mathrm{Co}, \mathrm{Cu}\right.$, or $\mathrm{Ni}$ and $m \mathrm{X}^{\mathrm{n}-}=$ counter ion $\left(\mathrm{SO}_{4}{ }^{2-}\right.$ or $\left.\left.\mathrm{Cl}^{-}\right)\right]$, and $(\mathrm{c})$ suggested desorption mechanism of the metal ions from the SPA surface.

the same as those described in Sections 2.4.1 and 2.4.2. The desorption efficiency $(D E)$ was calculated by Eq. (4):

$D E=\left(\frac{C_{\mathrm{e}, \mathrm{M}^{2+}} V_{\mathrm{HNO}_{3}}}{\mathrm{Q}_{\mathrm{T}, \mathrm{max}} W_{\mathrm{SPA}}}\right) \times 100$

where $D E(\%)$ is the desorption efficiency, $C_{\mathrm{e}, \mathrm{M}^{2+}}(\mathrm{mmol} / \mathrm{L})$ is the equilibrium concentration of the metal ion $\left(\mathrm{M}^{2+}\right), V_{\mathrm{HNO}}(\mathrm{L})$ is the volume of nitric acid solution, $Q_{T, \max }(\mathrm{mmol} / \mathrm{g})$ is the theoretical maximum adsorption capacity determined for each metal ion, and $w_{\text {SPA }}(\mathrm{g})$ is the weight of SPA loaded with each metal ion.

\subsubsection{Reuse of the spent SPA}

SPA adsorbents from desorption studies were washed with an excess of deionized water and isopropanol, before being dried in an oven at $95^{\circ} \mathrm{C}$ for $2.5 \mathrm{~h}$. Samples of SPA $(20.0 \mathrm{mg})$ were weighed into $250 \mathrm{~mL}$ Erlenmeyer flasks, and $100.0 \mathrm{~mL}$ of each metal-ion solution $(0.79 \mathrm{mmol} / \mathrm{L})$ was added. The optimal experimental parameters determined from adsorption studies were adopted. Further experimental procedures were the same as those described in Sections 2.4.1 and 2.4.2. The re-adsorption efficiency (RE) of SPA for a new cycle of adsorption of each metal ion was calculated using Eq. (5):

$$
\begin{aligned}
R E= & \frac{\left\{\left[\left(w_{\mathrm{SPA}, \mathrm{M}^{2+}}-w_{\mathrm{SPA}}\right) Q_{\mathrm{T}, \max }\right]_{\mathrm{des}}+\left(Q_{\max } w_{\mathrm{SPA}}\right)_{\mathrm{re}-\mathrm{ads}}\right\} / w_{\mathrm{SPA}}}{Q_{\mathrm{T}, \max }} \\
& \times 100
\end{aligned}
$$

where $R E(\%)$ is the re-adsorption efficiency, $w_{\mathrm{SPA}, \mathrm{M}^{2+}}(\mathrm{g})$ is the weight of SPA loaded with metal ion, $w_{\text {SPA }}(\mathrm{g})$ (inside brackets with subscript "des") is the weight of SPA after desorption, which is determined from $w_{\mathrm{SPA}, \mathrm{M}^{2+}}$ and the desorption efficiency (DE), $Q_{\max }$ $(\mathrm{mmol} / \mathrm{g})$ is the new maximum adsorption capacity obtained from the re-adsorption study, and $w_{\mathrm{SPA}}(\mathrm{g})$ is the weight of SPA used in the re-adsorption test. The subscripts "des" and "re-ads" in Eq. (5) are related to the desorption and re-adsorption tests, respectively.

\section{Results and discussion}

\subsection{Preparation and characterization of SPA adsorbent}

The characterization of SB and SPA adsorbent by thermogravimetric analysis (TGA) (Fig. S1 and Table S1) and scanning electron microscopy (SEM) (Fig. S2) can be accessed in the Supplementary material.

\subsubsection{Percent weight gain and number of carboxylic acid groups}

Fig. 1 presents the synthetic route used to obtain the SPA adsorbent, showing a suggestion of the adsorption mechanism through which metal ions $\left(\mathrm{M}^{2+}\right)$ are removed from aqueous solution by SPA adsorbent, and a suggestion of the desorption mechanism through which metal ions are desorbed from the SPA surface and released into the aqueous solution. The chemical modification of SB with PA using Py as a solvent and base/catalyst to produce SPA was optimized through the evaluation of the effects of reaction time and PA concentration on the values of $p w g$ and $n_{\mathrm{COOH}}$. The results of optimizing the esterification reaction are presented in Table 1 , which shows that, as the amount of PA was increased, pwg and 
Table 1

The results of optimizing the chemical modification of SB with PA.

\begin{tabular}{llll}
\hline $\begin{array}{l}\text { Phthalic anhydride } \\
(\mathrm{PA})(\mathrm{g})\end{array}$ & $\begin{array}{l}\text { Reaction } \\
\text { time }(\mathrm{h})\end{array}$ & \multicolumn{2}{l}{$\mathrm{SPA}^{\mathrm{a}}$} \\
\cline { 3 - 4 } & & $p w g(\%)$ & $n_{\mathrm{COOH}}(\mathrm{mmol} / \mathrm{g})$ \\
\hline 2.0 & 3 & $40.62 \pm 3.38$ & $2.42 \pm 0.18$ \\
4.0 & & $58.99 \pm 0.10$ & $2.71 \pm 0.08$ \\
6.0 & & $75.29 \pm 1.43$ & $3.26 \pm 0.03$ \\
8.0 & 3 & $81.22 \pm 2.84$ & $3.18 \pm 0.10$ \\
6.0 & 6 & $75.29 \pm 1.43$ & $3.26 \pm 0.03$ \\
& 1 & $62.71 \pm 3.35$ & $2.57 \pm 0.20$ \\
8.0 & 3 & $81.22 \pm 2.84$ & $3.18 \pm 0.10$ \\
& 6 & $98.06 \pm 1.25$ & $3.60 \pm 0.25$ \\
& 12 & $140.80 \pm 1.60$ & $4.95 \pm 0.02$ \\
& 18 & $142.90 \pm 14.09$ & $4.80 \pm 0.95$ \\
& 24 & $161.22 \pm 8.89$ & $4.99 \pm 0.47$ \\
\hline
\end{tabular}

a The weight of SB used in all chemical modifications was $1.0 \mathrm{~g}$. All reactions were performed in duplicate.

$n_{\mathrm{COOH}}$ also increased. The increase in the amount of PA from 2.0 to $8.0 \mathrm{~g}$ yielded an increase in both $p w g$ and $n_{\mathrm{COOH}}$. A small variation between the $n_{\mathrm{COOH}}$ values was observed for reactions employing 6.0 and $8.0 \mathrm{~g}$ of PA, considering the standard deviation. Therefore, when studying the esterification as a function of reaction time, 6.0 and $8.0 \mathrm{~g}$ of PA were also assessed with a view to a possible reduction in the preparation costs of the SPA adsorbent on a larger scale. For reactions employing $8.0 \mathrm{~g}$ of PA, as the reaction time increased, $p w g$ and $n_{\mathrm{COOH}}$ also increased. The same behavior was noticed for reactions using $6.0 \mathrm{~g}$ of PA. However, the $n_{\mathrm{COOH}}$ for the reaction employing $6.0 \mathrm{~g}$ of PA and a reaction time of $6 \mathrm{~h}$ was similar to that when using $8.0 \mathrm{~g}$ of PA and reaction times equal to or greater than $12 \mathrm{~h}$. Thus, to decrease the preparation costs of the SPA adsorbent, $6.0 \mathrm{~g}$ of $\mathrm{PA}(\mathrm{PA} / \mathrm{SB}$ ratio $=6: 1)$ and a reaction time of $6 \mathrm{~h}$ were chosen to prepare a larger amount of SPA adsorbent in order to perform the adsorption experiments. These reaction conditions were chosen by taking into account the highest $n_{\mathrm{COOH}}$ obtained using the smaller amount of PA and shorter reaction time. When increasing the reaction scale to $10.0 \mathrm{~g}$ of $\mathrm{SB}$ and $60.0 \mathrm{~g}$ of $\mathrm{PA}$, the $p w g$ and $n_{\mathrm{COOH}}$ values were $74.85 \%$ and $4.79 \pm 0.03 \mathrm{mmo} / \mathrm{g}$, respectively. The scale-up of the reaction resulted in a decrease in the $p w g$ by $2.98 \%$ and an increase in $n_{\mathrm{COOH}}$ by $0.63 \%$. The estimated preparation cost of $\mathrm{SPA}(\mathrm{PA} / \mathrm{SB}=6: 1$ and $6 \mathrm{~h}$ reaction time) based on the international market prices of the chemicals used, SB, and electricity in Brazil was US\$ 85.60 per kilogram of SPA. The preparation cost of SPA did not include the chemicals used in the elaboration steps (Section 2.2.1) and the possibility of recovering and recycling Py and excess PA.

Liu et al. (2006) also studied the esterification of SB with PA using Py as a base/solvent $(\mathrm{PA} / \mathrm{SB}$ ratio $=1: 1.5$ and $\mathrm{Py} / \mathrm{SB}$ ratio $=1: 10)$ under ultrasound irradiation at $115^{\circ} \mathrm{C}$ for $75 \mathrm{~min}$. They reported a maximum pwg of $39.1 \%$ when using the reaction conditions previously mentioned. In comparison to the results reported by Liu et al. (2006), SPAs were obtained in this study with higher pwg values.

\subsubsection{Elemental analysis and FTIR spectroscopy}

Elemental analysis was carried out for SB and SPA. The carbon, hydrogen, and nitrogen contents for SB and SPA were 46.56 and $48.62 \%, 5.09$ and $5.31 \%, 0.30$ and $0.19 \%$, respectively. Fig. 2a presents the FTIR spectra for SB and SPA. The major changes that can be highlighted in the spectrum of SB in relation to SPA are: (1) the appearance of a band at $3074 \mathrm{~cm}^{-1}$, which is attributed to an intramolecular bond between the hydrogen of the carboxylic acid group and the oxygen of the carbonyl ester group; (2) the appearance of bands at 2638 and $2527 \mathrm{~cm}^{-1}$, which are related to the stretching of hydrogen bonding exhibited by dimmers of aromatic carboxylic acid; (3) the appearance of a strong band at
$1724 \mathrm{~cm}^{-1}$, which corresponds to the stretching of conjugated carbonyl ester; (4) the appearance of bands at 1600 and $1491 \mathrm{~cm}^{-1}$, which are related to the stretching of $\mathrm{C}=\mathrm{C}$ bonds in the benzene ring of phthalate moiety and lignin; (5) a band at $1286 \mathrm{~cm}^{-1}$, related to the $\mathrm{C}-\mathrm{O}$ stretching in esters and carboxylic acids; and (6) a band at $745 \mathrm{~cm}^{-1}$ related to $\mathrm{C}-\mathrm{H}$ out-of-plane bending for the 1,2-substituted benzenoid ring (Pavia et al., 2014). The absence of bands at $1850-1800 \mathrm{~cm}^{-1}$ in the FTIR spectrum of SPA, which correspond to asymmetric and symmetric stretching modes of carbonyl group of cyclic carboxylic acid anhydride, indicates that SPA is free of unreacted PA (Liu et al., 2006; Pavia et al., 2014). These changes in the FTIR spectra of SPA in comparison with SB confirm the introduction of the phthalate moiety into SB through the esterification reaction. Similar IR band assignments were reported by de Melo et al. (2010) and Liu et al. (2006) who studied the esterification of microcrystalline cellulose and SB with PA, respectively.

Fig. $2 \mathrm{~b}$ presents the FTIR spectra for SPA and SPA loaded with $\mathrm{Co}^{2+}, \mathrm{Cu}^{2+}$, and $\mathrm{Ni}^{2+}$. The adsorption of metal ions on the SPA adsorbent was characterized by the splitting of the band in the region of $1685 \mathrm{~cm}^{-1}$ (Smith, 1998), which corresponds to the stretching of $\mathrm{C}=\mathrm{O}$ in carboxylic acid groups. This band appears to be overlapped with the ester band at $1724 \mathrm{~cm}^{-1}$. When the metal-ion adsorption takes place, this band is split and two new bands appear at 1592 and $1552 \mathrm{~cm}^{-1}$, corresponding to the asymmetric stretching of carboxylate groups. The band at $1592 \mathrm{~cm}^{-1}$ also appears to be overlapped with the stretching of $\mathrm{C}=\mathrm{C}$ bonds at $1600 \mathrm{~cm}^{-1}$ as seen in Fig. 2b for SPA-loaded with $\mathrm{Co}^{2+}, \mathrm{Cu}^{2+}$, and $\mathrm{Ni}^{2+}$. The splitting of the band at $1685 \mathrm{~cm}^{-1}$ is attributed to the carboxylic acid group and is indicative that these groups are deprotonated during the adsorption of metal ions and that the carboxylate groups are involved in the adsorption of metal ions (Łyszczek, 2007). These changes in the FTIR spectra for SPA in comparison with SPA loaded with $\mathrm{Co}^{2+}, \mathrm{Cu}^{2+}$, and $\mathrm{Ni}^{2+}$ prove that the adsorption mechanism involves an ion-exchange phenomenon, in which hydronium ions are exchanged by metal ions followed by complexation of the metal ions with carboxylate groups, as suggested in Fig. 1b.

\subsubsection{Point of zero charge (PZC)}

The PZC was determined to assess the surface properties of the SPA adsorbent. The $\mathrm{pH}$ that is required to yield a net zero surface charge may be related to the acidity constant $\left(K_{\mathrm{a}}\right)$ of an adsorbent material containing acidic functional groups (Noh and Schwarz, 1990). Thus, the surface of an adsorbent has a net positive surface charge at $\mathrm{pH}<\mathrm{PZC}$, whereas, at $\mathrm{pH}>\mathrm{PZC}$, it has a net negative surface charge. The PZC value for the SPA adsorbent was $2.92 \pm 0.06$. The $\mathrm{p} K_{\mathrm{a}}$ values of PA, corresponding to the position of carboxyl groups 1 and 2, are 2.98 and 5.28 (Fig. 1), respectively (Braude and Nachod, 1955). A comparison of the $\mathrm{p} K_{\mathrm{a}}$ values for PA and the PZC of SPA indicates that electronic effects provided by the presence of the ester bond between the hydroxyl groups of SB and the phthalate moiety influenced the acidity of the remaining carboxyl groups. The PZC value for the SPA adsorbent indicates that the adsorption of metal ions will occur at $\mathrm{pH} \geq 2.92$.

\subsubsection{Energy dispersive $X$-ray (EDX) spectroscopy}

EDX spectroscopy was used to map the surface of the SPA adsorbent in order to evaluate the adsorption sites of the adsorbed metal ions and their distribution along the surface of the SPA. Fig. 3a-c presents the distribution of $\mathrm{Co}^{2+}, \mathrm{Cu}^{2+}$, and $\mathrm{Ni}^{2+}$ on the surface of the SPA adsorbent. In Fig. 3a-c, a non-uniform distribution of adsorbed $\mathrm{Co}^{2+}, \mathrm{Cu}^{2+}$, and $\mathrm{Ni}^{2+}$ was observed at the adsorption surface sites of the SPA adsorbent. Some regions exhibited higher concentrations of metal ions than others. The Langmuir model better described the adsorption of $\mathrm{Co}^{2+}, \mathrm{Cu}^{2+}$, and $\mathrm{Ni}^{2+}$ on the SPA adsorbent, as pre- 

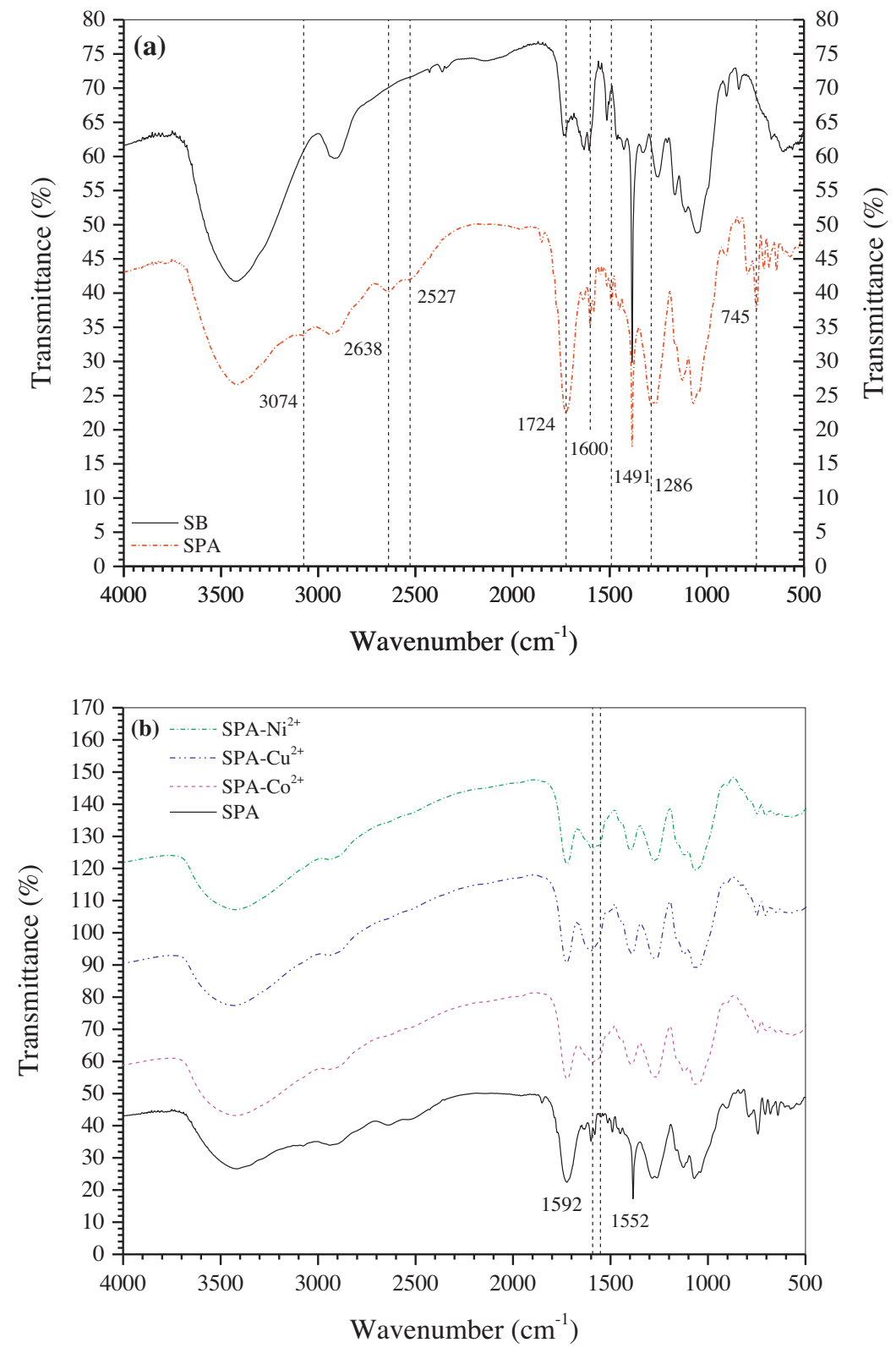

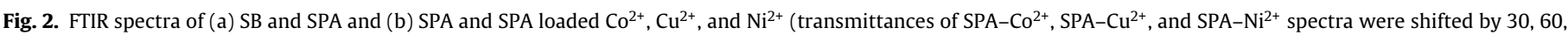
and $90 \%)$.

sented in Section 3.2.3.1. This suggests the formation of a uniform adsorption layer on the SPA surface. Conversely, in Fig. 3a-c, it can be seen that there are some preferential adsorption sites. However, the Langmuir model would still be representative, taking into account that there is no experimental evidence of multilayer formation, but merely the presence of sparse and preferential adsorption sites on the SPA surface. Similar results were reported by Liu and $\mathrm{Xu}$ (2007) for the biosorption of $\mathrm{Ni}^{2+}$ on aerobic granules and by Vieira and Beppu (2006) for the adsorption of $\mathrm{Hg}^{2+}$ on unmodified and modified cross-linked chitosan films.

\subsection{Adsorption experiments}

\subsubsection{Effect of the solution $\mathrm{pH}$ on metal-ion removal}

The effect of the solution $\mathrm{pH}$ on metal-ion removal by SPA was assessed at $25^{\circ} \mathrm{C}$ with a $0.79 \mathrm{mmol} / \mathrm{L}$ metal-ion solution, $130 \mathrm{rpm}$, $0.2 \mathrm{~g} / \mathrm{L}$ adsorbent, as well as $180 \mathrm{~min}$ equilibrium time $\left(t_{\mathrm{e}}\right)$, based on kinetic data (Table 2) for $\mathrm{Co}^{2+}, \mathrm{Cu}^{2+}$, and $\mathrm{Ni}^{2+}$. Figure 4 presents the equilibrium adsorption capacity $\left(q_{\mathrm{e}}\right)$ of $\mathrm{Co}^{2+}, \mathrm{Cu}^{2+}$, and $\mathrm{Ni}^{2+}$ on the SPA adsorbent as a function of the solution $\mathrm{pH}$ from 2.0 to 5.75. The removal of metal ions from aqueous solution is strongly controlled by the solution $\mathrm{pH}$, as the solution $\mathrm{pH}$ affects both the surface charge of the SPA adsorbent and the form of the metal ions in the aqueous solution. The net surface charge of an adsorbent in aqueous solution is associated with its PZC. The PZC value of the SPA adsorbent is 2.92. Therefore, the removal of metal ions was favored at $\mathrm{pH}>\mathrm{PZC}$, where the surface of the SPA adsorbent is negatively charged, owing to the deprotonation of carboxylic acid groups. Fig. 4 shows that the $q_{\mathrm{e}}$ increased as the solution $\mathrm{pH}$ increased, and a plateau was not attained for the removal of $\mathrm{Co}^{2+}, \mathrm{Cu}^{2+}$, and $\mathrm{Ni}^{2+}$. At low $\mathrm{pH}$ values $(\mathrm{pH}<3)$, the carboxylate groups on the SPA adsorbent surface were protonated and the removal of metal ions did not occur. For $\mathrm{pH}$ values higher than the $\mathrm{PZC}(\mathrm{pH} \geq 3)$, the removal of $\mathrm{Cu}^{2+}$ took place as a consequence of strong attractions between the negatively charged carboxylate groups containing nonbonding electron pairs on the SPA adsorbent surface and positively charged metal ions in 

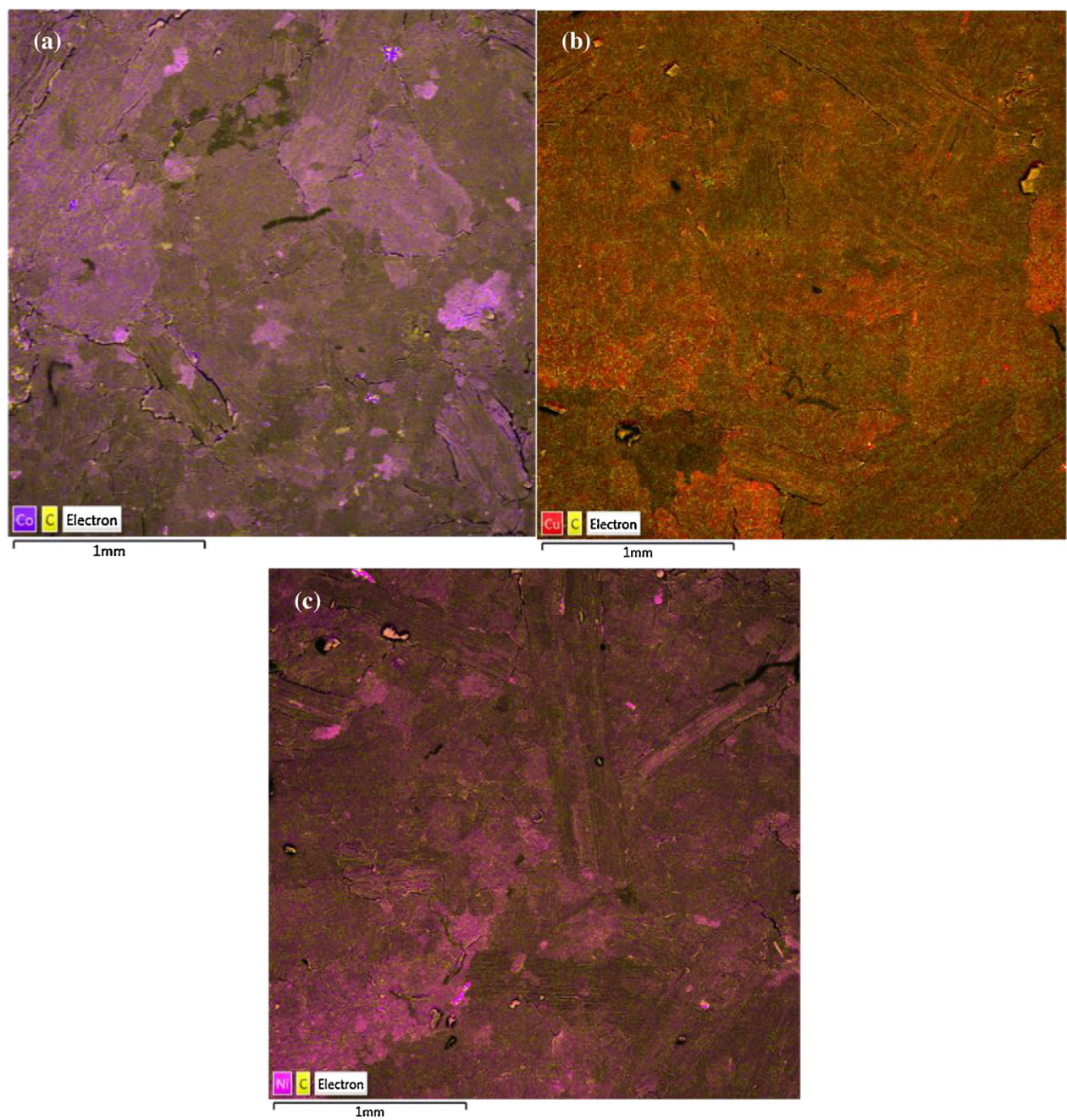

Fig. 3. SEM-EDX images with surface mapping for (a) $\mathrm{Co}^{2+}$, (b) $\mathrm{Cu}^{2+}$, and (c) $\mathrm{Ni}^{2+}$ adsorbed on the SPA surface.

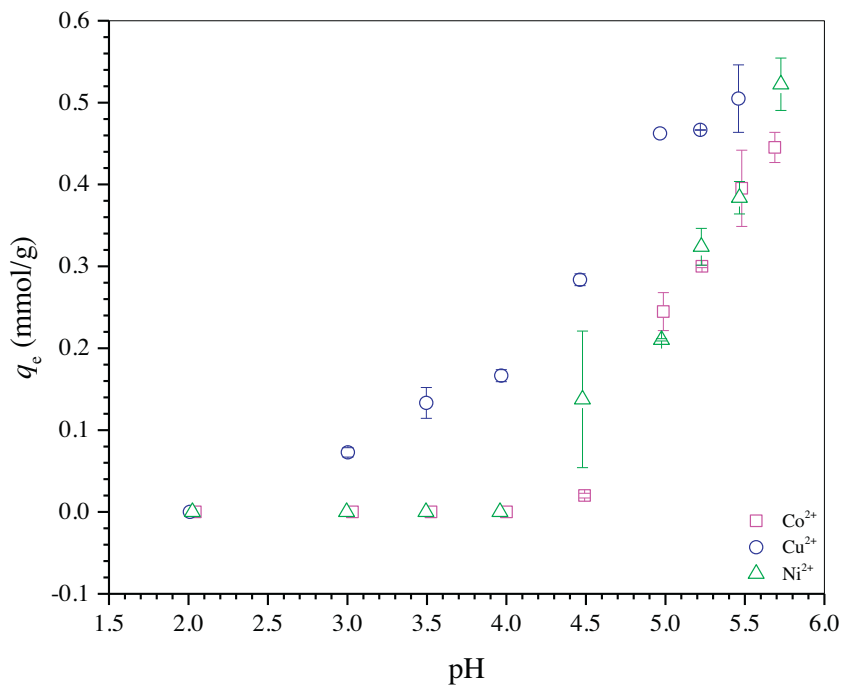

Fig. 4. Effect of $\mathrm{pH}$ on the adsorption of $\mathrm{Co}^{2+}, \mathrm{Cu}^{2+}$, and $\mathrm{Ni}^{2+}$ onto the SPA $(0.79$ $\mathrm{mmol} / \mathrm{L} \mathrm{M}^{2+}, 130 \mathrm{rpm}, 25^{\circ} \mathrm{C}, 0.2 \mathrm{~g} / \mathrm{L} \mathrm{SPA}$ and $180 \mathrm{~min}$ of shaking for $\mathrm{Co}^{2+}, \mathrm{Cu}^{2+}$, and $\mathrm{Ni}^{2+}$, respectively).

solution. Conversely, the removal of $\mathrm{Co}^{2+}$ and $\mathrm{Ni}^{2+}$ took place at $\mathrm{pH}$ values higher than 4 . This indicates that an alternative method to separate $\mathrm{Cu}^{2+}$ from $\mathrm{Co}^{2+}$ and $\mathrm{Ni}^{2+}$ is to control the solution $\mathrm{pH}$ at values below 4 . The maximum $q_{\mathrm{e}}$ value was attained at $\mathrm{pH} 5.5$ for $\mathrm{Cu}^{2+}$ and 5.75 for $\mathrm{Co}^{2+}$ and $\mathrm{Ni}^{2+}$. Adsorption at $\mathrm{pH}$ values greater than 5.5 for $\mathrm{Cu}^{2+}$ and 5.75 for $\mathrm{Co}^{2+}$ and $\mathrm{Ni}^{2+}$ was not evaluated, as the formation of metal-hydrolyzed species $\left[\mathrm{M}(\mathrm{OH})^{+}\right]$could occur with consequent precipitation of metal-ion hydroxides $\left[\mathrm{M}(\mathrm{OH})_{2(\mathrm{~s})}\right]$. Therefore, $\mathrm{pH}$ values of 5.5 for $\mathrm{Cu}^{2+}$ and 5.75 for $\mathrm{Co}^{2+}$ and $\mathrm{Ni}^{2+}$ were chosen as the maximum $\mathrm{pH}$ values for the following adsorption experiments, both as a function of time and initial metal-ion concentration.

\subsubsection{Adsorption kinetics}

The adsorption kinetics represents one of the most significant parameters for designing a wastewater treatment plant based on the batch adsorption process (Ho and McKay, 1999). Pseudo-first(see the Supplementary material) and pseudo-second-order kinetic models were used to model the adsorption rate of metal ions on the SPA adsorbent surface at $\mathrm{pH} 5.5$ for $\mathrm{Cu}^{2+}$ and 5.75 for $\mathrm{Co}^{2+}$ and $\mathrm{Ni}^{2+}$ at $25^{\circ} \mathrm{C}, 130 \mathrm{rpm}, 0.79 \mathrm{mmol} / \mathrm{L}$ metal-ion solution, and $0.2 \mathrm{~g} / \mathrm{L}$ adsorbent.

The pseudo - second - order kinetic model of Ho and McKay (1998) also expresses the rate of adsorption as a function of the adsorption capacity; however it assumes that the rate-limiting step may be chemical adsorption, involving valency forces through the sharing or exchange of electrons between adsorbent and adsor- 
Table 2

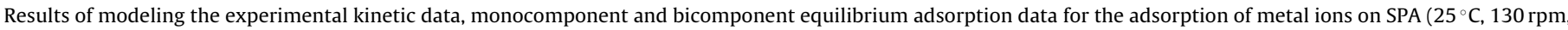
$0.2 \mathrm{~g} / \mathrm{L} \mathrm{SPA}$ ).

\begin{tabular}{|c|c|c|c|c|c|c|c|}
\hline \multicolumn{8}{|l|}{ Kinetic model } \\
\hline Experimental & Parameters & $\mathrm{Co}^{2+}$ & & $\mathrm{Cu}^{2+}$ & & $\mathrm{Ni}^{2+}$ & \\
\hline \multirow{3}{*}{ data } & $\mathrm{pH}$ & 5.75 & & 5.5 & & 5.75 & \\
\hline & $t_{\mathrm{e}}(\min )$ & 180 & & 180 & & 180 & \\
\hline & $q_{\mathrm{e}, \mathrm{e} \times \mathrm{p}}(\mathrm{mmol} / \mathrm{g})$ & $0.464 \pm 0.014$ & & $0.448 \pm 0.018$ & & $0.554 \pm 0.027$ & \\
\hline \multirow[t]{4}{*}{ Pseudo-second-order } & $q_{\mathrm{e}, \mathrm{est}}(\mathrm{mmol} / \mathrm{g})$ & $0.443 \pm 0.016$ & & $0.432 \pm 0.022$ & & $0.525 \pm 0.025$ & \\
\hline & $k_{2}(\mathrm{~g} / \mathrm{mmol} \mathrm{min})$ & $(4.20 \pm 0.82) \times 10^{-1}$ & & $(1.54 \pm 0.35) \times 10^{-1}$ & & $(1.89 \pm 0.43) \times 10^{-1}$ & \\
\hline & $R^{2}$ & 0.9218 & & 0.9222 & & 0.9404 & \\
\hline & $\chi_{\text {red }}^{2}$ & 0.0034 & & 0.0051 & & 0.0066 & \\
\hline \multicolumn{8}{|c|}{ Monocomponent isotherms } \\
\hline \multirow{7}{*}{$\begin{array}{l}\text { Experimental } \\
\text { data }\end{array}$} & Parameters & $\mathrm{Co}^{2+}$ & & $\mathrm{Cu}^{2+}$ & & $\mathrm{Ni}^{2+}$ & \\
\hline & $Q_{\text {max,exp }}(\mathrm{mmol} / \mathrm{g})$ & $0.462 \pm 0.021$ & & $0.845 \pm 0.006$ & & $0.701 \pm 0.017$ & \\
\hline & $\mathrm{pH}$ & 5.75 & & 5.5 & & 5.75 & \\
\hline & $t_{\mathrm{e}}(\min )$ & 180 & & 180 & & 180 & \\
\hline & $C N$ & 10.36 & & 5.67 & & 6.84 & \\
\hline & $I_{\mathrm{e}}(\mathrm{mol} / \mathrm{L})$ & 0.0512 & & 0.0523 & & 0.0526 & \\
\hline & $\gamma_{e}$ & 0.886 & & 0.886 & & 0.886 & \\
\hline \multirow[t]{5}{*}{ Langmuir } & $Q_{\text {max,est }}(\mathrm{mmol} / \mathrm{g})$ & $0.561 \pm 0.027$ & & $0.935 \pm 0.061$ & & $0.932 \pm 0.052$ & \\
\hline & $b(\mathrm{~L} / \mathrm{mmol})$ & $7.24 \pm 0.90$ & & $7.09 \pm 1.21$ & & $3.01 \pm 0.33$ & \\
\hline & $R^{2}$ & 0.9658 & & 0.9388 & & 0.9800 & \\
\hline & $\chi^{2}$ red & 0.0022 & & 0.0075 & & 0.0022 & \\
\hline & $\Delta_{\text {ads }} G^{\circ}$ & $-22.33 \pm 2.76$ & & $-22.28 \pm 3.79$ & & $-20.16 \pm 2.19$ & \\
\hline \multirow[t]{4}{*}{ Freundlich } & $K_{\mathrm{F}}\left[\mathrm{mmol} / \mathrm{g} /(\mathrm{L} / \mathrm{mmol})^{1 / n}\right]$ & $0.556 \pm 0.031$ & & $0.973 \pm 0.034$ & & $0.759 \pm 0.017$ & \\
\hline & $n$ & $2.57 \pm 0.23$ & & $2.37 \pm 0.12$ & & $1.90 \pm 0.06$ & \\
\hline & $R^{2}$ & 0.9198 & & 0.9685 & & 0.9892 & \\
\hline & $\chi_{\text {red }}^{2}$ & 0.0052 & & 0.0039 & & 0.0012 & \\
\hline \multicolumn{8}{|c|}{ Bicomponent isotherms } \\
\hline \multirow{8}{*}{$\begin{array}{l}\text { Experimental } \\
\text { data }\end{array}$} & Parameters & $\mathrm{Co}-\mathrm{Cu}$ & $\mathrm{Cu}-\mathrm{Co}$ & $\mathrm{Co}-\mathrm{Ni}$ & $\mathrm{Ni}-\mathrm{Co}$ & $\mathrm{Cu}-\mathrm{Ni}$ & $\mathrm{Ni}-\mathrm{Cu}$ \\
\hline & $Q_{\text {max,exp,i }}(\mathrm{mmol} / \mathrm{g})$ & $0.152 \pm 0.014$ & $0.505 \pm 0.019$ & $0.180 \pm 0.007$ & $0.281 \pm 0.006$ & $0.627 \pm 0.007$ & $0.532 \pm 0.019$ \\
\hline & $Q_{\max , \exp , \mathrm{i}+\mathrm{j}}(\mathrm{mmol} / \mathrm{g})$ & $0.657 \pm 0.024$ & & $0.461 \pm 0.009$ & & $1.159 \pm 0.020$ & \\
\hline & $Q_{\text {max,exp,i,multi }} / Q_{\max , \text { exp,mono }}$ & 0.329 & 0.598 & 0.390 & 0.401 & 0.742 & 0.759 \\
\hline & $\mathrm{pH}$ & 5.5 & 5.5 & 5.5 & 5.5 & 5.5 & 5.5 \\
\hline & $t_{\mathrm{e}, \mathrm{mono}}(\mathrm{min})$ & 180 & 180 & 180 & 180 & 180 & 180 \\
\hline & $I_{\mathrm{e}}(\mathrm{mol} / \mathrm{L})$ & 0.0536 & & 0.0537 & & 0.0557 & \\
\hline & $\gamma_{\mathrm{e}}$ & 0.886 & & 0.886 & & 0.886 & \\
\hline Modified & $\eta_{\mathrm{i}}$ & $2.161 \pm 0.382$ & $7.089 \pm 0.126$ & $1.613 \pm 0.199$ & $1.132 \pm 0.128$ & $0.714 \pm 0.100$ & $2.050 \pm 0.221$ \\
\hline extended & $\eta_{\mathrm{j}}$ & $0.956 \pm 0.303$ & $1.521 \pm 0.512$ & $0.399 \pm 0.074$ & $1.601 \pm 0.344$ & $0.781 \pm 0.218$ & $42.40 \pm 80.26$ \\
\hline Lang- & $R^{2}$ & 0.8069 & 0.9289 & 0.9126 & 0.9511 & 0.9404 & 0.9100 \\
\hline muir & $\chi_{\text {red }}^{2}$ & 0.0031 & 0.0034 & 0.0016 & 0.0014 & 0.0038 & 0.0063 \\
\hline \multirow[t]{5}{*}{$P$-Factor } & $P_{i}$ & 2.857 & 1.629 & 2.693 & 2.672 & 1.437 & 1.114 \\
\hline & $K_{\mathrm{L}, i}$ & $6.20 \pm 1.28$ & $12.72 \pm 1.72$ & $6.958 \pm 0.974$ & $6.653 \pm 0.708$ & $11.69 \pm 1.43$ & $1.545 \pm 0.179$ \\
\hline & $a_{\mathrm{L}, i}(\mathrm{~L} / \mathrm{mmol})$ & $11.05 \pm 3.21$ & $13.61 \pm 2.70$ & $12.40 \pm 2.25$ & $7.14 \pm 1.18$ & $12.50 \pm 2.07$ & $1.658 \pm 0.441$ \\
\hline & $R^{2}$ & 0.8268 & 0.9298 & 0.9018 & 0.9554 & 0.9321 & 0.9106 \\
\hline & $\chi_{\text {red }}^{2}$ & 0.0028 & 0.0034 & 0.0018 & 0.0013 & 0.0044 & 0.0063 \\
\hline
\end{tabular}

bate (Ho and McKay, 1999). The model of Ho and McKay (1998) is shown in Eq. (6):

$\frac{\mathrm{d} q_{\mathrm{t}}}{\mathrm{dt}}=k_{2}\left(q_{\mathrm{e}}-q_{\mathrm{t}}\right)^{2}$

where $q_{\mathrm{e}}$ and $q_{\mathrm{t}}(\mathrm{mmol} / \mathrm{g})$ are the adsorption capacities at equilibrium $t_{\mathrm{e}}$ and at time $t$ (min), respectively, and $k_{2}(\mathrm{~g} / \mathrm{mmol}$.min) is the pseudo-second-order rate constant. Rearranging and integrating Eq. (6) using boundary conditions $q_{\mathrm{t}}=0$ at $t=0$ and $q_{\mathrm{t}}=q_{\mathrm{t}}$ at $t=t$, yields Eq. (7).

$q_{\mathrm{t}}=\frac{k_{2} q_{\mathrm{e}}^{2} t}{1+k_{2} q_{\mathrm{e}} t}$

The experimental kinetic data were modeled by nonlinear regression analysis using pseudo - first - and pseudo - second - order kinetic models with Microcal OriginPro ${ }^{\circledR} 2015$ software, which was set to use the Levenberg-Marquardt iteration algorithm and the weight method statistical [Eq. (8)]. The weights were used to minimize the chi-squared $\left(\chi^{2}\right)$ value [Eq. (9)] in order to obtain the best fitting curve. Both the coefficient of determination $\left(R^{2}\right)$ and reduced $\chi^{2}$ [Eq. (10)] were taken into account to evaluate the quality of the nonlinear regression analysis and to define the best kinetic model for describing the adsorption process.

$w_{\mathrm{i}}=\frac{1}{y_{\mathrm{i}}}$ where $w_{\mathrm{i}}$ is the weighting coefficient and $y_{\mathrm{i}}$ is the experimental data point.

$\chi^{2}=\sum_{i=1}^{N} w_{\mathrm{i}}\left(y_{\mathrm{i}}-\hat{y_{\mathrm{i}}}\right)^{2}$

where $\hat{y}_{\mathrm{i}}$ is the theoretical data point calculated by the model.

$x_{\text {red }}^{2}=\frac{x^{2}}{v}$

where $\chi^{2}$ red is the reduced chi-squared and $v$ is the number of degrees of freedom.

Table 2 presents the kinetic parameters obtained by modeling the experimental kinetic data with pseudo-second-order kinetic model using nonlinear regression analysis. Results of modeling kinetic data with pseudo-first-order model and experimental kinetic data are available in Tables S2 and S3 (see the Supplementary Material). Fig. 5a-c presents plots of $q_{\mathrm{t}}$ versus $t$ for the adsorption of $\mathrm{Co}^{2+}, \mathrm{Cu}^{2+}$, and $\mathrm{Ni}^{2+}$ onto the SPA adsorbent, and the curves fitted to the experimental data using pseudo-first- and pseudo-second-order kinetic models are shown. Table 2 shows that both the values of $R^{2}$ and $\chi^{2}$ red obtained by fitting the pseudo-second-order model to the experimental data were higher and lower in comparison with the pseudo-first-order model (Table S2), respectively. Additionally, when the experimental equilibrium 

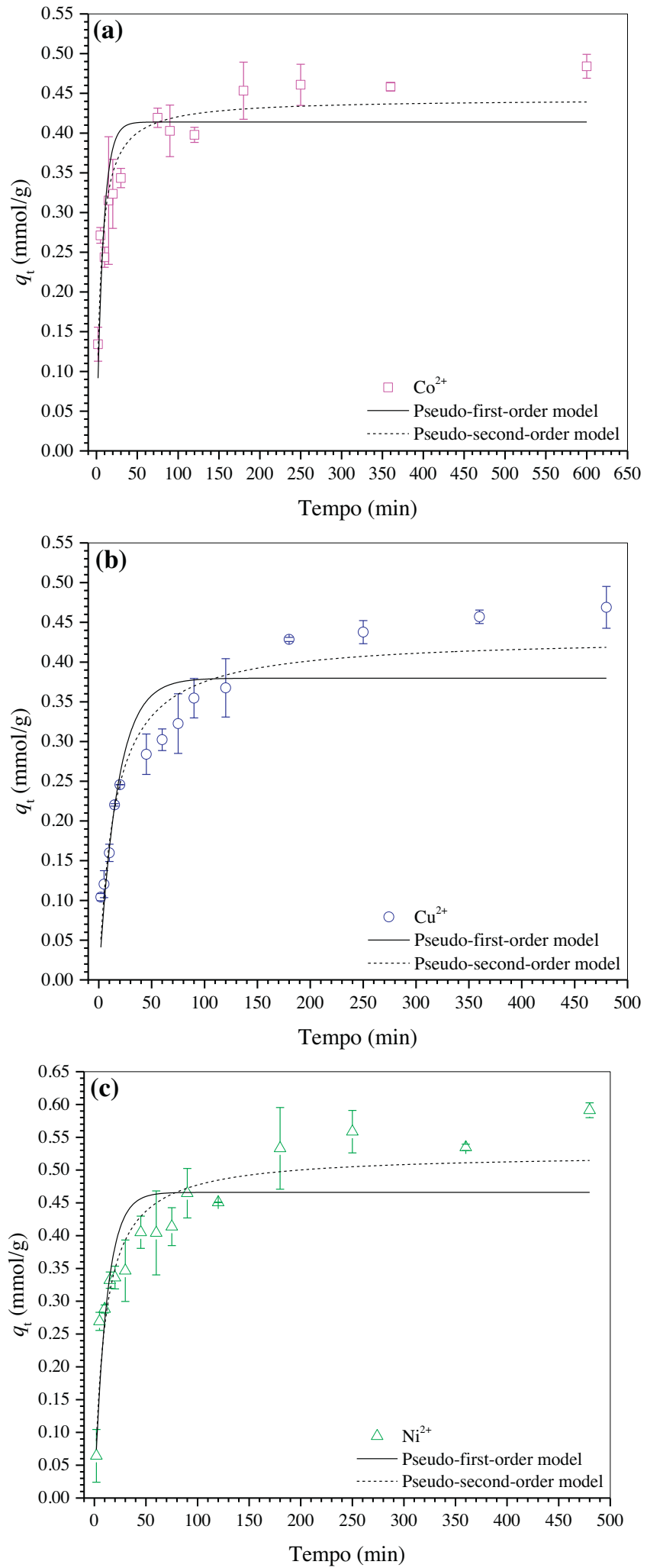

Fig. 5. Adsorption kinetics of (a) $\mathrm{Co}^{2+}$, (b) $\mathrm{Cu}^{2+}$, and (c) $\mathrm{Ni}^{2+}$ on the SPA at pH 5.75 for $\mathrm{Co}^{2+}$ and $\mathrm{Ni}^{2+}$ and 5.5 for $\mathrm{Cu}^{2+}, 0.79 \mathrm{mmol} / \mathrm{L} \mathrm{M}^{2+}, 25^{\circ} \mathrm{C}, 130 \mathrm{rpm}$ and $0.2 \mathrm{~g} / \mathrm{L} \mathrm{SPA}$.

adsorption capacity $\left(q_{\mathrm{e}, \mathrm{exp}}\right)$ was compared to the estimated equilibrium adsorption capacity $\left(q_{\mathrm{e}, \mathrm{est}}\right)$, it could be seen that the values provided by the pseudo-second-order model were more similar than those provided by the pseudo-first-order model. This suggests that the pseudo-second-order model better describes the adsorption kinetics of $\mathrm{Co}^{2+}, \mathrm{Cu}^{2+}$, and $\mathrm{Ni}^{2+}$ on the SPA adsorbent.

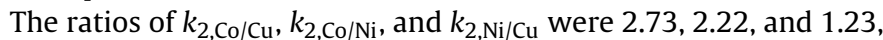
respectively. This means that $\mathrm{Co}^{2+}$ is adsorbed by SPA faster than $\mathrm{Cu}^{2+}$ and $\mathrm{Ni}^{2+}$, whereas $\mathrm{Ni}^{2+}$ is adsorbed more quickly by SPA than $\mathrm{Cu}^{2+}$. These findings suggest that it would be possible to make a kinetic separation of $\mathrm{Co}^{2+}$ from $\mathrm{Cu}^{2+}$ and $\mathrm{Ni}^{2+}$ in a multicomponent ion solution if a low agitation time is used in a batch-mode system. The separation of $\mathrm{Co}^{2+}, \mathrm{Cu}^{2+}$, and $\mathrm{Ni}^{2+}$ from aqueous solutions is often required in hydrometallurgy processing (Pośpiech and Walkowiak, 2007) and industrial wastes, for example, in acid mine drainage (Yavuz et al., 2003).

\subsubsection{Adsorption isotherms}

Adsorption isotherms describe how different kinds of pollutants interact with adsorbents and, therefore, are very important in the clarification of adsorption mechanisms as well as in determining the equilibrium adsorption capacity and its influence on the surface properties on adsorption. Hence, adsorption isotherms are essential in the design of batch adsorption systems (Ferreira et al., 2015; Foo and Hameed, 2010). Adsorption of $\mathrm{Co}^{2+}, \mathrm{Cu}^{2+}$, and $\mathrm{Ni}^{2+}$ on the SPA adsorbent was investigated in mono- and bicomponent aqueous solutions at $25^{\circ} \mathrm{C}, 130 \mathrm{rpm}, 0.2 \mathrm{~g} / \mathrm{L} \mathrm{SPA}, 0.05-1.12 \mathrm{mmol} / \mathrm{L}$ metal-ion solution, with an equilibrium time of $180 \mathrm{~min}$ (based on the kinetic studies of Section 3.2.2).

3.2.3.1. Monocomponent adsorption. Monocomponent isotherm models of Langmuir, Freundlich, Sips, and Redlich-Peterson (R-P) have been used to describe the equilibrium features of adsorption (Srivastava et al., 2006). For theoretical approaches of the Sips and Redlich-Peterson isotherm models see the Supplementary material.

The Freundlich isotherm model (Freundlich, 1906) assumes adsorption on a heterogeneous surface with a non-uniform distribution of adsorption heat over the adsorbent surface. Whereas, the Langmuir isotherm model (Langmuir, 1918) assumes adsorption on a homogeneous surface with the adsorption sites having identical energy or equal affinity to the adsorbate (Srivastava et al., 2006).

The Freundlich isotherm is given by Eq. (11):

$q_{\mathrm{e}}=K_{\mathrm{F}} C_{\mathrm{e}}{ }^{1 / n}$

where $K_{\mathrm{F}}$ is the Freundlich constant $\left[(\mathrm{mmol} / \mathrm{g})(\mathrm{L} / \mathrm{mmol})^{1 / n}\right]$ and $n$ is the heterogeneity factor (Srivastava et al., 2006).

The Langmuir isotherm is given by Eq. (12):

$q_{\mathrm{e}}=\frac{Q_{\max } b C_{\mathrm{e}}}{1+b C_{\mathrm{e}}}$

where $b(\mathrm{~L} / \mathrm{mmol})$ is the Langmuir constant related to the adsorption energy or affinity of the adsorbate for the adsorption site and $Q_{\max }$ is the maximum adsorption capacity ( $\mathrm{mmol} / \mathrm{g}$ ).

The change in adsorption free energy of the system $\left(\Delta_{\mathrm{ads}} G^{\circ}\right)$ can be calculated using Eq. (13):

$\Delta_{\mathrm{ads}} G^{\circ}=-R T \ln K_{\mathrm{a}}$

where $K_{\mathrm{a}}$ is the thermodynamic equilibrium constant (dimensionless), $T(\mathrm{~K})$ is the absolute temperature, and $R$ is the ideal gas constant $(8.314 \mathrm{~J} / \mathrm{K} \mathrm{mol})$.

According to Liu (2009), the thermodynamic equilibrium constant can be calculated from Langmuir constant, $b$, using the approach shown in Eq. (14):

$K_{\mathrm{a}}=\left[\frac{b}{\gamma_{\mathrm{e}}}(1 \mathrm{~mol} / \mathrm{L})\right]$

where $\gamma_{\mathrm{e}}$ is the activity coefficient at equilibrium (dimensionless) at $25^{\circ} \mathrm{C}$. 
If the adsorbate is a metal ion, the activity coefficient is strongly affected and promptly decreases as the ionic strength increases. Therefore, it is crucial to correct the activity coefficient for each adsorption system evaluated using the extended Debye-Hückel law [Eq. (15)] to provide a correct calculation of $\Delta_{\text {ads }} G^{\circ}$ (Liu, 2009).

$\log \gamma_{\mathrm{e}}=\frac{-0.509 z^{2} \sqrt{I_{\mathrm{e}}}}{1+\alpha \sqrt{I_{\mathrm{e} / 305}}}$

where $z$ is the charge of the metal ion, $I_{\mathrm{e}}(\mathrm{mol} / \mathrm{L})$ is the ionic strength at equilibrium, and $\alpha(\mathrm{pm})$ is the ion size (considered to be $600 \mathrm{pm}$ for $\mathrm{Co}^{2+}, \mathrm{Cu}^{2+}$, and $\mathrm{Ni}^{2+}$ ) (Harris, 2010). The ionic strength was calculated using the first equilibrium concentration data point of the plateau of the mono- and bicomponent adsorption isotherms. Monocomponent experimental data were modeled through nonlinear regression analysis of the Langmuir, Freundlich, Sips, and R-P isotherm models using Microcal OriginPro ${ }^{\circledR} 2015$ software. The monocomponent isotherm model parameters were found by minimizing the reduced $\chi^{2}$ value, as shown in Section 3.2.2. The equilibrium monocomponent adsorption isotherms for the removal of $\mathrm{Co}^{2+}, \mathrm{Cu}^{2+}$, and $\mathrm{Ni}^{2+}$ using the SPA adsorbent at $25^{\circ} \mathrm{C}$, $130 \mathrm{rpm}$, and $0.2 \mathrm{~g} / \mathrm{L}$ SPA are presented in Fig. $6 \mathrm{a}-\mathrm{c}$. Monocomponent adsorption was evaluated at $\mathrm{pH} 5.5$ for $\mathrm{Cu}^{2+}$ and 5.75 for $\mathrm{Co}^{2+}$ and $\mathrm{Ni}^{2+}$. Table 2 shows the results of modeling the experimental adsorption data through nonlinear regression analysis for the two monocomponent isotherm models. The results of modeling the experimental adsorption data with the Sips and Redlich-Peterson models and experimental isotherm data are available in Tables S2 and S4 (see the Supplementary material). As shown in Table 2, considering the values of $Q_{\text {max,exp }}, Q_{\text {max,est }}, R^{2}$, and $\chi^{2}$ red, as well as the shape of the isotherm curves shown in Fig. $6 a-c$, the adsorption of $\mathrm{Co}^{2+}, \mathrm{Cu}^{2+}$, and $\mathrm{Ni}^{2+}$ was best described by the Langmuir model. However, considering the values of $R^{2}$ and $\chi^{2}$ red, the adsorption of $\mathrm{Cu}^{2+}$ and $\mathrm{Ni}^{2+}$ seems to be better described by the Sips model. Conversely, the Sips model exhibited a higher $R^{2}$ value and smaller $\chi^{2}$ red value for the adsorption of $\mathrm{Cu}^{2+}$ and $\mathrm{Ni}^{2+}$; the value of $Q_{\text {max,est }}$ in comparison with $Q_{\max \text {,exp }}$ was overestimated by this model. Furthermore, also by analyzing the values of $R^{2}$ and $\chi^{2}$ red, the adsorption of $\mathrm{Cu}^{2+}$ and $\mathrm{Ni}^{2+}$ seemed again to be better described by the Freundlich and R-P models in comparison to the Langmuir model. However, the Freundlich and R-P models do not seem to represent the plateau of the isotherm curves for the adsorption of $\mathrm{Cu}^{2+}$ and $\mathrm{Ni}^{2+}$ very well, exhibiting a tendency to overestimate the maximum adsorption capacity of the SPA adsorbent. In addition, the R-P exponents $(\beta)$ for the adsorption of $\mathrm{Cu}^{2+}$ and $\mathrm{Ni}^{2+}$ were closer to unity than zero, thus closely approximating the Langmuir model. The $n$ parameter of Sips also suggested that the adsorption systems involving adsorption of $\mathrm{Cu}^{2+}$ and $\mathrm{Ni}^{2+}$ presented a certain degree of heterogeneity.

In fact, the SPA adsorbent has a heterogeneous surface, where the adsorption sites are mostly composed of carboxylic acid groups from the phthalate moiety. The other functional groups present on the SPA surface, which can present a capacity for adsorbing metal ions, are the phenolic and carboxylic acid groups in lignin. Therefore, the surface of the SPA adsorbent is not only composed of adsorption sites that have identical affinity to the adsorbates. Thus, the interpretation of such adsorption system is not so simple, and the adsorption of $\mathrm{Co}^{2+}, \mathrm{Cu}^{2+}$, and $\mathrm{Ni}^{2+}$ cannot be seen as fully Langmuirian. In addition, the analysis of the Scatchard plot (Fig. 6a-c) for adsorption of $\mathrm{Co}^{2+}, \mathrm{Cu}^{2+}$, and $\mathrm{Ni}^{2+}$ on the SPA adsorbent reveals profiles exhibiting multilinearity, which are related to the presence of different binding sites presenting different affinities toward metal ions. These binding sites are divided into type-1 (high-affinity, $H$ ) and type-2 (low-affinity, L) (Anirudhan and Suchithra, 2010). The binding constants $(b)$ and estimated maximum adsorption capacities $\left(Q_{\text {max,est }}\right)$ of $H$ and $L$ binding sites were calculated and are given in Table S2. As seen in Table S2, binding sites exhibiting high-affinity were related to low-capacity binding sites, whereas those exhibiting low-affinity were related to high-capacity. According to Anirudhan and Suchithra (2010), carboxyl groups exhibiting low $\mathrm{p} K_{\mathrm{a}}$ values and different conformations for metal binding may exhibit different affinities toward metal ions, thereby confirming the heterogeneity of the adsorption sites on the SPA adsorbent. However, although the Langmuir model failed to fully describe the adsorption system to a certain degree, and its use to estimate the adsorption constants for comparison purposes is very desirable.

The value of the Sips parameter, $n$, for the adsorption of $\mathrm{Cu}^{2+}$ and $\mathrm{Ni}^{2+}$ is greater than unity, which differs from the parameter $n$ for the adsorption of $\mathrm{Co}^{2+}$. As the Sips isotherm constant, $n$, can be used as an estimation of the heterogeneity of the adsorption system, it suggests that the adsorption of $\mathrm{Cu}^{2+}$ and $\mathrm{Ni}^{2+}$ is more heterogeneous than $\mathrm{Co}^{2+}$. As the Sips isotherm is a combination of Langmuir and Freundlich isotherms, the values of $n$ for the adsorption of $\mathrm{Co}^{2+}, \mathrm{Cu}^{2+}$, and $\mathrm{Ni}^{2+}$ suggest that the adsorption system is more Langmuirian than Freundlichian. According to experimental equilibrium data and the Langmuir model, the maximum metal-ion adsorption capacity of the SPA adsorbent adopted the following order $\mathrm{Cu}^{2+}>\mathrm{Ni}^{2+}$ " $\mathrm{Co}^{2+}$. As the monocomponent adsorption systems were best described by the Langmuir model, the modified Langmuir models were used to evaluate and interpret the bicomponent adsorption data, which are shown in the next Section.

As shown in Table 2, the coordination numbers (CNs) were higher than unity. This indicates that more than one carboxylate group is being used to adsorb a metal ion. The values of the CNs exhibited the following order $\mathrm{Co}^{2+}{ }$ $\mathrm{Ni}^{2+}>\mathrm{Cu}^{2+}$. The difference between physisorption and chemisorption is apparent in the magnitude of the changes in enthalpy and free energy of adsorption. Generally, the magnitude of the change in free energy for physisorption is smaller than that of chemisorption (Yu et al., 2001). The change in free energy of adsorption for physisorption ranges from -20 to $0 \mathrm{~kJ} / \mathrm{mol}$ and chemisorption from -80 to $-400 \mathrm{~kJ} / \mathrm{mol}$ (Húmpola et al., 2013; Yu et al., 2001). The values of $\Delta_{\mathrm{ads}} \mathrm{G}^{\circ}$ for the adsorption of $\mathrm{Co}^{2+}, \mathrm{Cu}^{2+}$, and $\mathrm{Ni}^{2+}$ on the SPA adsorbent were in the range from -20.2 to $-22.3 \mathrm{~kJ} / \mathrm{mol}$, which are slightly higher than those expected for physisorption and much lower than those expected for chemisorption. This indicates that a mixed mechanism may be controlling the removal of $\mathrm{Co}^{2+}, \mathrm{Cu}^{2+}$, and $\mathrm{Ni}^{2+}$ from aqueous solution by the SPA adsorbent. Further evidence of the adsorption mechanism was provided by FTIR spectrum of SPA in comparison with spectra of SPA loaded with $\mathrm{Co}^{2+}, \mathrm{Cu}^{2+}$, and $\mathrm{Ni}^{2+}$, as earlier discussed in Section 3.1.2. Based on the changes in free energy of adsorption and FTIR spectra, it is suggested that the adsorption mechanism is controlled by two steps: (1) ion-exchange, in which hydronium ions are exchanged with metal ions and (2) complexation, where metal ions are complexed by carboxylate groups through the sharing of nonbonding electron pairs of negatively charged oxygen atoms with metal ions. However, as discussed in Section 3.3, the desorption data of SPA loaded with $\mathrm{Co}^{2+}, \mathrm{Cu}^{2+}$, and $\mathrm{Ni}^{2+}$ indicate that fairly weak bonds are formed between the carboxylate groups and the metal ions studied. Thus, these results confirm that the adsorption mechanism involves a contribution of both physisorption and chemisorption, as ion-exchange is a characteristic phenomenon of physisorption and complexation is a characteristic phenomenon of chemisorption (Ünlü and Ersoz, 2006). The energy required in the former lies in the magnitude of the physisorption (Ferreira et al., 2015), whereas the energy involved in the latter is dependent on the magnitude of chemisorption. Other evidence lies in the fact that the activation energy required for desorption is large and the removal of the chemisorbed species from the surface may only be possible under suitable conditions, for example, 

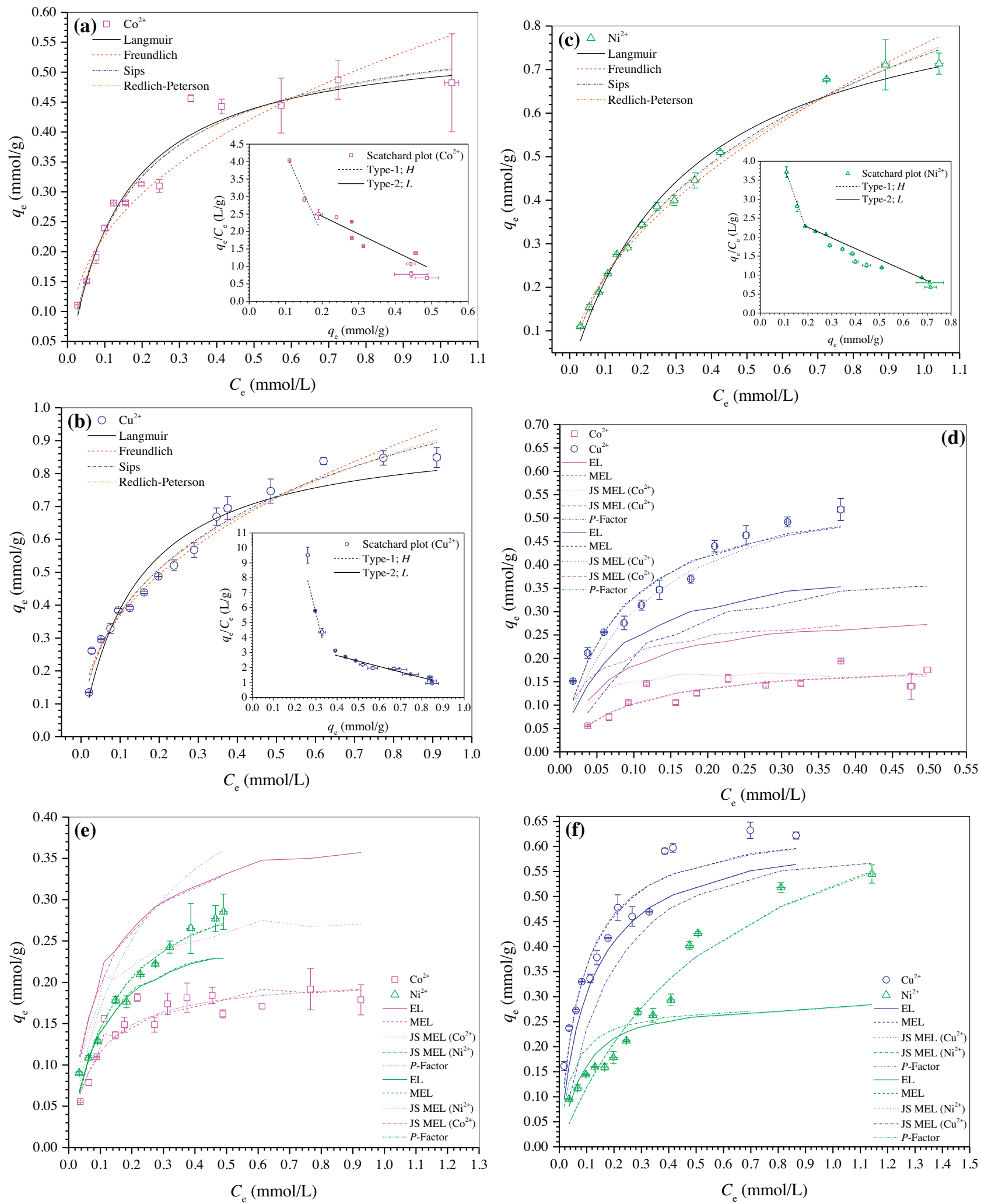

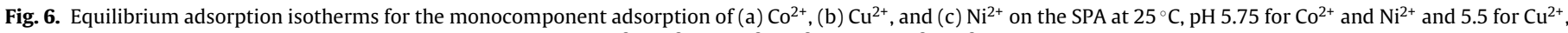

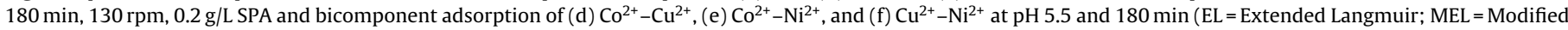
Extended Langmuir; JS MEL = Jain and Snoeyink Modified Extended Langmuir).

through chemical treatment of the surface, which was performed in this study by using $1.0 \mathrm{~mol} / \mathrm{L} \mathrm{HNO}_{3}$ as the desorbing solution.
3.2.3.2. Bicomponent adsorption. Three bicomponent adsorption systems $\mathrm{Co}^{2+}-\mathrm{Cu}^{2+}, \mathrm{Co}^{2+}-\mathrm{Ni}^{2+}$, and $\mathrm{Cu}^{2+}-\mathrm{Ni}^{2+}$ were studied and modeled using four models: (1) the nonmodified competitive Langmuir model, (2) the Jain and Snoeyink (J-S) modified extended 
Langmuir model, (3) P-Factor, and (4) the modified extended Langmuir model with an interaction factor. The binary metal-ion systems were equimolar $\left(C_{i}=C_{j}\right)$ with concentrations varying from 0.05 to $1.12 \mathrm{mmol} / \mathrm{L}$. For theoretical approach of the nonmodified competitive Langmuir and Jain and Snoeyink (J-S) modified extended Langmuir models see the Supplementary material.

The $P$-Factor is a model developed by McKay and Al Duri (1987). It assumes the same concepts as the Langmuir isotherm model and is described by Eq. (16):

$q_{\mathrm{e}, i, \text { multi }}=\frac{1}{P_{i}}\left(\frac{K_{\mathrm{L}, i} C_{\mathrm{e}, i, \text { multi }}}{1+a_{\mathrm{L}, i} C_{\mathrm{e}, i, \text { multi }}}\right)$

where $P_{i}$ was termed by McKay and Al Duri (1987) as a "lumped" capacity factor, which can be defined as shown in Eq. (17):

$P_{i}=\frac{\left(K_{\mathrm{L}, i} / a_{\mathrm{L}, i}\right)_{\text {mono }}}{\left(K_{\mathrm{L}, i} / a_{\mathrm{L}, i}\right)_{\text {multi }}}=\frac{Q_{\text {max, mono }}}{Q_{\text {max, multi }}}$

where $\left(K_{\mathrm{L}, i} / a_{\mathrm{L}, i}\right)_{\text {mono }}$ and $\left(K_{\mathrm{L}, i} / a_{\mathrm{L}, i}\right)_{\text {multi }}$ are the maximum adsorption capacities for component $i$ in a monocomponent and multicomponent adsorption system, respectively.

The modified extended competitive Langmuir model (Mathews and Weber, 1980) is also an extension of the Langmuir isotherm model for a component $i$ in an adsorption system with $N$ components. However, this model incorporates an interaction factor, $\eta$, as shown in Eq. (18):

$$
q_{\mathrm{e}, i}=\frac{Q_{\max , i} b_{i}\left(C_{\mathrm{e}, i} / \eta_{i}\right)}{1+\sum_{j=1}^{N} b_{j}\left(C_{\mathrm{e}, j} / \eta_{j}\right)}
$$

where $\eta_{i}$ and $\eta_{j}$ are the interaction factors that can be estimated from the nonlinear regression of competitive adsorption data using $Q_{\max , i}, Q_{\max , j}, b_{i}$, and $b_{j}$ from the monocomponent Langmuir isotherm.

The multicomponent adsorption isotherm models were evaluated using the monocomponent parameters determined from the nonlinear regression analysis of the monocomponent equilibrium adsorption data (Table S4) using the Langmuir model [Eq. (12)], as shown in Tables 2 and S2. Microsoft Excel ${ }^{\circledR} 365$ software for Windows ${ }^{\circledR}$ was used to determine the values of $R^{2}$ and $\chi^{2}$ red for the nonmodified competitive Langmuir and J-S modified extended Langmuir models using the multicomponent equilibrium adsorption data (Tables S2 and S5) for each metal ion. The interaction factor $(\eta)$ of the modified extended Langmuir model was determined by nonlinear regression analysis of the multicomponent equilibrium adsorption data (Table S5) by minimizing $\chi^{2}$ red with Microcal OriginPro ${ }^{\circledR} 2015$ software and using the procedures described in Section 3.2.2. The value of $Q_{\max \text {,multi }}$ used to determine the parameter $P_{i}$ was obtained from the nonlinear regression analysis of the multicomponent equilibrium adsorption data, using the Langmuir model [Eq. (12)] and Microcal OriginPro ${ }^{\circledR} 2015$ software, as previously mentioned. The results of modeling the multicomponent equilibrium adsorption data with multicomponent models are presented in Tables 2 and S2.

Bicomponent adsorption studies were performed at $\mathrm{pH} 5.5$, $130 \mathrm{rpm}, 25^{\circ} \mathrm{C}, 0.2 \mathrm{~g} / \mathrm{L} \mathrm{SPA}$, and with an equimolar concentration of metal ions in binary mixtures. Fig. $6 \mathrm{~d}-\mathrm{f}$ presents the graphs for the binary adsorption systems $\mathrm{Co}^{2+}-\mathrm{Cu}^{2+}, \mathrm{Co}^{2+}-\mathrm{Ni}^{2+}$, and $\mathrm{Cu}^{2+}-\mathrm{Ni}^{2+}$, respectively. The equilibrium adsorption data for bicomponent metal-ion systems can also be analyzed in terms of $Q_{\max }$ for a metal ion, $i$, in the presence of another metal ion, $j$, or when metal ion $i$ is present alone in the aqueous solution $\left(Q_{\max , \exp , i, \operatorname{mult}} / Q_{\max , \text { exp,mono }}\right)$. When $Q_{\text {max,exp,i,multi }} / Q_{\text {max,exp,mono }}>1$, the adsorption of metal ion $i$ is promoted by the presence of the metal ion $j$. When $Q_{\text {max,exp,i,multi }} / Q_{\text {max,exp,mono }}=1$, there is no observable net interaction between metal ions $i$ and $j$. When $Q_{\max , \exp , i, \operatorname{mult}} / Q_{\max , \exp , m o n o}$ $<1$, the adsorption of metal ion $i$ is suppressed by the presence of metal ion $j$ (Ronda et al., 2013). As shown in Table 2, the adsorption of all metal ions was suppressed by the presence of another metal ion. However, in the binary system involving $\mathrm{Co}^{2+}$ and $\mathrm{Cu}^{2+}$, there was greater the adsorption of $\mathrm{Cu}^{2+}$ compared to the adsorption of $\mathrm{Co}^{2+}$, whereas in the binary system involving $\mathrm{Co}^{2+}$ and $\mathrm{Ni}^{2+}$, the adsorption of $\mathrm{Co}^{2+}$ was less than $\mathrm{Ni}^{2+}$. In the binary system composed of $\mathrm{Cu}^{2+}$ and $\mathrm{Ni}^{2+}$, the adsorption of $\mathrm{Cu}^{2+}$ was greater than the adsorption of $\mathrm{Ni}^{2+}$. The Pearson parameter $(\delta)$ for $\mathrm{Co}^{2+}$, $\mathrm{Ni}^{2+}$, and $\mathrm{Cu}^{2+}$ equals $0.130,0.126$, and 0.104 (Pearson, 1973), respectively. Thus, the hardness of the metal ions follows the order $\mathrm{Co}^{2+}>\mathrm{Ni}^{2+}>\mathrm{Cu}^{2+}$. The carboxylate group of the phthalate moiety grafted on the SPA adsorbent behaves as a very weakly basic, negatively charged, oxygen-donor group that can be stabilized by resonance. The $\mathrm{Co}^{2+}, \mathrm{Ni}^{2+}$, and $\mathrm{Cu}^{2+}$ ions are considered borderline Lewis acids, whereas a carboxylate ligand, such as an acetate ion, is considered as a hard Lewis base. In terms of the hard and soft acid base (HSAB) concept, the carboxylate ligands should exhibit a preference for harder metal ions. However, according to the Irving and Williams (1953) series, which discusses the relative stabilities of complexes formed between transition-metal ions and ligands, carboxylate ligands form more stable complexes with metal ions in the following order $\mathrm{Cu}^{2+}>\mathrm{Ni}^{2+}>\mathrm{Co}^{2+}$. The obtained results are in good agreement with the Irving and Williams series, and for the monocomponent and multicomponent adsorption systems the maximum adsorption capacities follow the order $\mathrm{Cu}^{2+}>\mathrm{Ni}^{2+}>\mathrm{Co}^{2+}$.

The adsorption data, as a function of solution $\mathrm{pH}$, contact time (kinetics), and initial metal-ion concentration, indicate that there is the possibility to partially separate $\mathrm{Cu}^{2+}$ from $\mathrm{Co}^{2+}$ and $\mathrm{Ni}^{2+}$ by utilizing the effect of solution $\mathrm{pH}$ and $\mathrm{Ni}^{2+}$ from $\mathrm{Co}^{2+}$ through kinetic $\left(k_{2, \mathrm{Co}^{2+}}{ }^{2+} k_{2, \mathrm{Ni}}{ }^{2+}=2.22\right)$ and thermodynamic control $\left(Q_{\text {max,est,multi }}\right.$; see Table 2 ). The mono- and bicomponent adsorption data obtained in this study could be used to design a fixed-bed column in order to study the removal of $\mathrm{Co}^{2+}, \mathrm{Cu}^{2+}$, and $\mathrm{Ni}^{2+}$ from mono- and multicomponent aqueous solutions and to evaluate the possibility of separating these metal ions.

The $\Delta_{\text {ads }} G^{\circ}$ values for the multicomponent systems were similar to those for the monocomponent systems. This indicates that multicomponent adsorption was also favorable and spontaneous. As shown in Table 2 by comparing the three bicomponent adsorption systems, higher $R^{2}$ and lower $\chi^{2}$ red values were obtained by modeling the equilibrium adsorption data with modified extended Langmuir and $P$-Factor models. Nonmodified extended Langmuir and $\mathrm{J}-\mathrm{S}$ modified extended Langmuir models showed a worse fit to the experimental data (see Table S2 in the Supplementary material). These results confirm that there are interactions between the metal ions in the bicomponent systems studied. Figure S3 presents the graphs of $q_{\mathrm{e}, \text { est }}$ against $q_{\mathrm{e}, \exp }$ for the bicomponent adsorption systems studied. Table S6 presents the slopes and intercepts of the plots of $q_{\mathrm{e} \text {,est }}$ against $q_{\mathrm{e}, \mathrm{exp}}$ for the bicomponent systems studied. As shown in Fig. S3a-f, most of the equilibrium adsorption data points are distributed around the $45^{\circ}$ dashed line, with a $95 \%$ confidence interval, for the modified extended Langmuir and $P$-Factor models. The slopes and intercepts for the bicomponent systems composed of $i-j$ and $j-i$ metal ions were closer to unity and zero, respectively, for the modified extended Langmuir and $P$-Factor models in comparison with nonmodified extended Langmuir and J-S modified extended Langmuir models. This indicates that the modified extended Langmuir and $P$-Factor models can predict the values of $q_{\mathrm{e}, \text { est }}$ from experimental data very well.

The maximum metal-ion adsorption capacity in the bicomponent systems $\left(Q_{\max , \exp , i+j}\right)$ (Table 2$)$ were lower than the sum of 
Table 3

Comparison of $Q_{\max }$ for the removal of $\mathrm{Co}^{2+}, \mathrm{Cu}^{2+}$, and $\mathrm{Ni}^{2+}$ by various adsorbents reported in the literature.

\begin{tabular}{|c|c|c|c|c|c|c|c|c|}
\hline \multirow{2}{*}{$\begin{array}{l}\text { Adsorbent } \\
\text { abbreviation }\end{array}$} & \multirow{2}{*}{$\begin{array}{l}\text { Type of solid } \\
\text { support }\end{array}$} & \multirow[t]{2}{*}{ Ligand type } & \multirow[t]{2}{*}{$\mathrm{pH}$} & \multirow{2}{*}{$\begin{array}{l}\text { Equilibrium } \\
\text { time (min) }\end{array}$} & \multicolumn{3}{|c|}{$Q_{\max }(\mathrm{mmol} / \mathrm{g})^{\mathrm{a}}$} & \multirow[t]{2}{*}{ Reference } \\
\hline & & & & & $\mathrm{Co}^{2+}$ & $\mathrm{Cu}^{2+}$ & $\mathrm{Ni}^{2+}$ & \\
\hline SPA & Sugarcane bagasse & Carboxylic acid & $5.5-5.75$ & 180 & 0.561 & 0.935 & 0.932 & This study \\
\hline STA & Sugarcane bagasse & Carboxylic acid & $5.5-5.75$ & $180,250,75$ & 1.140 & 1.197 & 1.563 & Ramos et al. (2015) \\
\hline CSIS & Chitosan & Amine/amide/azomethine & 5.0 & 180 & 0.908 & 1.623 & 0.684 & Monier et al. (2010) \\
\hline PET-g-(MAA/AAm) & $\begin{array}{l}\text { Poly(ethylene } \\
\text { terephthalate) } \\
\text { (PET) }\end{array}$ & Carboxylic acid/amide & 5.0 & 120 & 0.461 & 0.492 & 0.741 & $\begin{array}{l}\text { Coşkun et al. } \\
(2006)\end{array}$ \\
\hline Sp-HPBA & $\begin{array}{l}\text { Sporopollenin (Sp) } \\
\text { of Lycopodium } \\
\text { clavatum }\end{array}$ & Phenolic/imine & $5-6$ & 90 & 0.039 & 0.043 & 0.036 & Çimen et al. (2013) \\
\hline $\begin{array}{l}\text { Palygorskite } \\
\text { (Brazil) }\end{array}$ & Palygorskite & Silanol & - & 1440 & 1.27 & 1.57 & 1.72 & $\begin{array}{l}\text { Oliveira et al. } \\
\text { (2013) }\end{array}$ \\
\hline BANPA & $\begin{array}{l}\text { Banana } \\
\text { pseudostem }\end{array}$ & Carboxylic acid & $\sim 6$ & $120,120,60$ & 0.56 & 0.49 & 0.55 & $\begin{array}{l}\text { Rodrigues et al. } \\
(2013)\end{array}$ \\
\hline BANMA & $\begin{array}{l}\text { Banana } \\
\text { pseudostem }\end{array}$ & Carboxylic acid & $\sim 6$ & $180,120,120$ & 0.27 & 0.29 & 0.47 & $\begin{array}{l}\text { Rodrigues et al. } \\
\text { (2013) }\end{array}$ \\
\hline PAMMAm & $\begin{array}{l}\text { Synthetic polymer } \\
\text { matrix }\end{array}$ & $\begin{array}{l}\text { Nitrogen from } \\
\text { aniline/alkylamide }\end{array}$ & $5.5-6.0$ & 30 & 0.122 & 0.201 & 0.104 & $\begin{array}{l}\text { Kushwaha et al. } \\
\text { (2013) }\end{array}$ \\
\hline Sil-NSuc & Silica gel & Amine/carboxylic acid & 5.5 & - & 1.85 & 1.04 & 1.89 & $\begin{array}{l}\text { Arakaki et al. } \\
(2013)\end{array}$ \\
\hline Celam biopolymer & Cellulose & $\begin{array}{l}\text { Aliphatic amine/nitrogen } \\
\text { of pyridine }\end{array}$ & $\sim 6$ & - & 0.097 & 0.102 & 0.077 & $\begin{array}{l}\text { Silva Filho et al. } \\
\text { (2013) }\end{array}$ \\
\hline
\end{tabular}

${ }^{\text {a }}$ Maximum adsorption capacities obtained from the Langmuir model at $25^{\circ} \mathrm{C}$, except for Palygorskite adsorbent ( $30^{\circ} \mathrm{C}$ ).

the single maximum adsorption capacities for each metal ion. Similar results were reported by Srivastava et al. (2006), who studied the adsorption of $\mathrm{Cd}^{2+}$ and $\mathrm{Zn}^{2+}$ on bagasse fly ash in mono- and bicomponent systems. According to Srivastava et al. (2006), the lower maximum adsorption capacities observed for bicomponent systems in comparison with monocomponent systems are a result of the presence of a variety of adsorption sites on the adsorbent surface, which exhibits partially specific affinity to the single metal ions. These observations seem to infringe upon the assumptions of the Langmuir theory, that is, the adsorbent surface is composed of homogeneous adsorption sites, so there should be no preferential adsorption or lateral interactions between adsorbates, and the adsorption sites exhibit equal affinities to the adsorbate. Although the Langmuir theory fails to fully describe the adsorption behavior of bicomponent systems, the use of the modified extended Langmuir model seemed reasonable, as the interaction factor incorporated the deviations from the nonmodified extended Langmuir model and its assumptions. The $P$-Factor model does not account for competition or interactions between the metal ions that influence adsorption (Choy et al., 2000). These competitions and interactions result in deviations in the estimation of the equilibrium adsorption capacity $\left(q_{\mathrm{e}}\right)$. However, the $P$-Factor model provided a good estimation of $q_{\mathrm{e}, \mathrm{est}}$ in comparison with $q_{\mathrm{e}, \exp }$ (Table S6). This good estimation could be obtained because we used the "lumped" factor, $P_{i}$, which provides a major enhancement over the extended Langmuir model, as reported by Choy et al. (2000). As shown in Table S6, the estimation of the $q_{\mathrm{e}}$ values by the $P$-Factor model was better than those predicted by the modified extended Langmuir model, which agrees with the conclusions reported by Choy et al. (2000).

\subsection{Desorption and reuse of the spent SPA adsorbent}

Desorption studies of SPA loaded with $\mathrm{Co}^{2+}, \mathrm{Cu}^{2+}$, and $\mathrm{Ni}^{2+}$ were carried out in batch mode at $25^{\circ} \mathrm{C}$ and $130 \mathrm{rpm}$ with $20.0 \mathrm{~mL}$ of $1.0 \mathrm{~mol} / \mathrm{L} \mathrm{HNO}_{3}, 20.0 \mathrm{mg}$ of spent adsorbent, and a contact time of $5 \mathrm{~min}$. The desorption efficiency $(D E)$ was $100 \%$ for the SPA adsorbents loaded with $\mathrm{Co}^{2+}, \mathrm{Cu}^{2+}$, and $\mathrm{Ni}^{2+}$.

The $\mathrm{pH}$ of the $1.0 \mathrm{~mol} / \mathrm{L} \mathrm{HNO}_{3}$ solution was zero. At this $\mathrm{pH}$ value, there is a high concentration of hydronium ions $\left(\mathrm{H}_{3} \mathrm{O}^{+}\right)$, which can be exchanged with metal ions through the protonation of carboxylate groups in the phthalate moiety. Therefore, the suggested mechanism for the desorption process of metal ions from SPA loaded with $\mathrm{Co}^{2+}, \mathrm{Cu}^{2+}$, and $\mathrm{Ni}^{2+}$ is that of ion-exchange, as shown in Fig. 1c.

The re-adsorption studies were carried out using the SPA adsorbents that were treated with $1.0 \mathrm{~mol} / \mathrm{L} \mathrm{HNO}_{3}$ for $5 \mathrm{~min}$ in the desorption studies described above. The re-adsorption studies were carried out using the best adsorption conditions that were determined from earlier adsorption studies as a function of solution $\mathrm{pH}\left(\mathrm{pH} 5.5\right.$ for $\mathrm{Cu}^{2+}$ and 5.75 for $\mathrm{Co}^{2+}$ and $\mathrm{Ni}^{2+}$ ) and contact time $\left(180 \mathrm{~min}\right.$ for $\mathrm{Co}^{2+}, \mathrm{Cu}^{2+}$, and $\mathrm{Ni}^{2+}$ ) with $100.0 \mathrm{~mL}$ of 0.79 $\mathrm{mmol} / \mathrm{L}$ metal-ion solution and $20.0 \mathrm{mg}$ of the spent SPA adsorbent. Re-adsorption studies demonstrate that the efficiency of re-adsorption ( $R E$ ) was $100 \%$ for all of the metal ions studied. These results indicate that the SPA adsorbent can be recovered and reused without loss of the adsorption capacity, and that the metal ions can also be recovered. The possibility of recovering both the SPA adsorbent and the metal ions would certainly improve the economic feasibility of an adsorption process using the SPA adsorbent.

\subsection{Comparisons with previously published data}

For comparison purposes, Table 3 presents several adsorbent materials that have previously been reported to remove $\mathrm{Co}^{2+}, \mathrm{Cu}^{2+}$ and $\mathrm{Ni}^{2+}$ from aqueous solutions in batch mode. Comparing the SPA adsorbent with some previously reported adsorbents used for the adsorption of $\mathrm{Co}^{2+}, \mathrm{Cu}^{2+}$, and $\mathrm{Ni}^{2+}$, it is reasonable to suggest that the SPA adsorbent is one of the most efficient adsorbents recently synthesized for this purpose.

\section{Conclusions}

The chemical modification of sugarcane bagasse (SB) with phthalic anhydride (PA) was studied as a function of PA amount and reaction time. Taking into account the preparation costs of $S B$ modified with PA (SPA), a reaction time of $6 \mathrm{~h}$ and a PA-to-SB ratio of $6: 1$ were chosen. This condition yielded SPA with a percent weight gain of $77.08 \%$ and an amount of carboxylic acid groups of $4.76 \mathrm{mmol} / \mathrm{g}$ The SPA adsorbent was effective in removing $\mathrm{Co}^{2+}, \mathrm{Cu}^{2+}$, and $\mathrm{Ni}^{2+}$ 
from mono- and bicomponent aqueous solutions. Kinetic studies revealed that the equilibrium adsorption time required for the removal of all metal ions was $180 \mathrm{~min}$ and a pseudo-second-order model was the best model to describe the adsorption kinetics. The monocomponent adsorption was well described by the Langmuir model and the maximum adsorption capacities were found to be $0.561,0.935$, and 0.932 for $\mathrm{Co}^{2+}, \mathrm{Cu}^{2+}$, and $\mathrm{Ni}^{2+}$, respectively. The change in free energy of adsorption $\left(\Delta_{\mathrm{ads}} G^{\circ}\right)$ values were found to be between -20.16 and $-22.33 \mathrm{~kJ} / \mathrm{mol}$, suggesting that a mixed mechanism controlled the adsorption of all metal ions by SPA. The adsorption capacity of SPA in the bicomponent system was lower, owing to suppressing interactions between metal ions. Desorption studies showed that SPA can be fully desorbed and recovered for a new adsorption cycle without loss of the adsorption capacity.

\section{Acknowledgments}

The authors are grateful to Universidade Federal de Ouro Preto (UFOP grant number 23.109.006271/2014-70) and Fundação de Amparo à Pesquisa do Estado de Minas Gerais (FAPEMIG grant number CEX APQ-00149/12) for funding this research. The authors are also grateful to Coordenação de Aperfeiçoamento de Pessoal de Nivel Superior (CAPES). The authors would like to acknowledge the Nanolab Electronic Microscopy Laboratory, at the Redemat, Escola de Minas, UFOP, MG, Brazil, for providing the equipment and technical support for experiments involving electron microscopy and $\mathrm{B}$. S. Ney P. Sampaio for SEX-EDX analyses. The authors are also grateful to Fernanda J. Gonçalves and Megg M. C. Elias for their help in running some adsorption experiments. This work is a collaboration research project of members of the Rede Mineira de Química (RQ-MG) supported by FAPEMIG (Project: CEX - RED-00010-14).

\section{Appendix A. Supplementary data}

Supplementary data associated with this article can be found, in the online version, at http://dx.doi.org/10.1016/j.indcrop.2015.10. 035.

\section{References}

Anirudhan, T., Suchithra, P., 2010. Equilibrium, kinetic and thennodynamic modeling for the adsorption of heavy metals onto chemically modified hydrotalcite. Indian J. Chem. Technol. 17, 247-259.

Arakaki, L.N.H., Filha, V.L.S.A., Germano, A.F.S., Santos, S.S.G., Fonseca, M.G., Sousa, K.S., Espínola, J.G.P., Arakaki, T., 2013. Silica gel modified with ethylenediamine and succinic acid-adsorption and calorimetry of cations in aqueous solution. Thermochim. Acta 556, 34-40.

Barakat, M.A., 2011. New trends in removing heavy metals from industrial wastewater. Arabian J. Chem. 4, 361-377.

Boamah, P.O., Huang, Y., Hua, M., Zhang, Q., Wu, J., Onumah, J., Sam-Amoah, L.K. Boamah, P.O., 2015. Sorption of heavy metal ions onto carboxylate chitosan derivatives-a mini-review. Ecotoxicol. Environ. Saf. 116, 113-120.

Braude, E.A., Nachod, F.C., 1955. Determination of Organic Structures by Physical Methods. Academic Press Inc., New York, USA

Çimen, A., Bilgiç, A., Kursunlu, A.N., Gübbük, İ.H., Uçan, H.İ., 2013. Adsorptive removal of $\mathrm{Co}(\mathrm{II}), \mathrm{Ni}(\mathrm{II})$, and $\mathrm{Cu}(\mathrm{II})$ ions from aqueous media using chemically modified sporopollenin of Lycopodium clavatum as novel biosorbent. Desalin. Water Treat. 52, 4837-4847.

Coşkun, R., Soykan, C., Saçak, M., 2006. Adsorption of copper(II), nickel(II) and cobalt(II) ions from aqueous solution by methacrylic acid/acrylamide monomer mixture grafted poly(ethylene terephthalate) fiber. Sep. Purif. Technol. 49, 107-114.

Choy, K.K.H., Porter, J.F., McKay, G., 2000. Langmuir isotherm models applied to the multicomponent sorption of acid dyes from effluent onto activated carbon. J. Chem. Eng. Data 45, 575-584.

Dąbrowski, A., Hubicki, Z., Podkościelny, P., Robens, E., 2004. Selective removal of the heavy metal ions from waters and industrial wastewaters by ion-exchange method. Chemosphere 56, 91-106.

de Melo, J.C.P., da Silva Filho, E.C., Santana, S.A.A., Airoldi, C., 2010. Exploring the favorable ion-exchange ability of phthalylated cellulose biopolymer using thermodynamic data. Carbohyd. Res. 345, 1914-1921.
Dumrul, H., Kursunlu, A.N., Kocyigit, O., Guler, E., Ertul, S., 2011. Adsorptive removal of $\mathrm{Cu}(\mathrm{II})$ and $\mathrm{Ni}(\mathrm{II})$ ions from aqueous media by chemical immobilization of three different aldehydes. Desalination 271, 92-99.

Ferreira, B.C.S., Teodoro, F.S., Mageste, A.B., Gil, L.F., de Freitas, R.P., Gurgel, L.V.A. 2015. Application of a new carboxylate-functionalized sugarcane bagasse for adsorptive removal of crystal violet from aqueous solution: Kinetic, equilibrium and thermodynamic studies. Ind. Crop. Prod. 65C, 521-534.

Foo, K.Y., Hameed, B.H., 2010. Insights into the modeling of adsorption isotherm systems. Chem. Eng. J. 156, 2-10.

Freundlich, H.M.F., 1906. Over the adsorption in solution. Z Phys. Chem.-Stoch. Ve 57, 385-470.

Fu, F., Wang, Q., 2011. Removal of heavy metal ions from wastewaters: a review. J. Environ. Manag. 92, 407-418.

Hancock, R.D., Martell, A.E., 1989. Ligand design for selective complexation of metal ions in aqueous solution. Chem. Rev. 89, 1875-1914.

Harris, D.C., 2010. Quantitative Chemical Analysis, 8th ed. W. H. Freeman, New York.

Haynes, W.M., 2014. CRC Handbook of Chemistry and Physics, 95th ed. Taylor \& Francis.

Ho, Y.S., McKay, G., 1998. Kinetic models for the sorption of dye from aqueous solution by wood. Process Saf. Environ. Prot. 76, 183-191.

Ho, Y.S., McKay, G., 1999. Pseudo-second order model for sorption processes. Process Biochem. 34, 451-465.

Húmpola, P.D., Odetti, H.S., Fertitta, A.E., Vicente, J.L., 2013. Thermodynamic analysis of adsorption models of phenol in liquid phase on different activated carbons. J. Chil. Chem. Soc. 58, 1541-1544.

Irving, H., Williams, R.J.P., 1953. The stability of transition-metal complexes. J. Chem. Soc., 3192-3210.

Kazemipour, M., Ansari, M., Tajrobehkar, S., Majdzadeh, M., Kermani, H.R., 2008. Removal of lead, cadmium, zinc, and copper from industrial wastewater by carbon developed from walnut, hazelnut, almond, pistachio shell, and apricot stone. J. Hazard. Mater. 150, 322-327.

Klaassen, C., 2008. Casarett \& Doull's Toxicology: The Basic Science of Poisons: The Basic Science of Poisons, 7th ed. McGraw-Hill, New York.

Ko, Y.G., Khasbaatar, A.D., Choi, U.S., Kim, J.-Y., 2010. Molecular interaction mechanism in solid polymer electrolyte comprising cellulose phthalate and LiClO4. Solid State Ion. 181, 1178-1182.

Kursunlu, A.N., Guler, E., Dumrul, H., Kocyigit, O., Gubbuk, I.H., 2009. Chemical modification of silica gel with synthesized new Schiff base derivatives and sorption studies of cobalt (II) and nickel (II). Appl. Surf. Sci. 255, 8798-8803.

Kushwaha, A.K., Gupta, N., Chattopadhyaya, M.C., 2013. Dynamics of adsorption of $\mathrm{Ni}(\mathrm{II}), \mathrm{Co}(\mathrm{II})$ and $\mathrm{Cu}(\mathrm{II})$ from aqueous solution onto newly synthesized poly[ $N$-(4-[4-(aminophenyl)methylphenylmethacrylamide])]. Arab. J. Chem., http://dx.doi.org/10.1016/j.arabjc.2013.1006.1007.

Langmuir, I., 1918. The adsorption of gases on plane surfaces of glass, mica and platinum. J. Am. Chem. Soc. 40, 1361-1403.

Liu, C.F., Sun, R.C., Ye, J., 2006. Structural and thermal characterization of sugarcane bagasse phthalates prepared with ultrasound irradiation. Polym. Deg. Stab. 91, 280-288.

Liu, Y., 2009. Is the free energy change of adsorption correctly calculated? J. Chem. Eng. Data 54, 1981-1985.

Liu, Y., Xu, H., 2007. Equilibrium, thermodynamics and mechanisms of $\mathrm{Ni}^{2+}$ biosorption by aerobic granules. Biochem. Eng. J. 35, 174-182.

Łyszczek, R., 2007. Thermal and spectroscopic investigations of new lanthanide complexes with 1,2,4-benzenetricarboxylic acid. J. Therm. Anal. Calorim. 90, 533-539.

Mathews, A.P., Weber, W.J., 1980. Mathematical Modeling of Adsorption in Multicomponent Systems Adsorption and Ion Exchange with Synthetic Zeolites. American Chemical Society, pp. 27-53.

McKay, G., Al Duri, B., 1987. Simplified model for the equilibrium adsorption of dyes from mixtures using activated carbon. Chem. Eng. Process. Process Intensif. 22, 145-156.

Monier, M., Ayad, D.M., Wei, Y., Sarhan, A.A., 2010. Adsorption of Cu(II), Co(II), and $\mathrm{Ni}(\mathrm{II})$ ions by modified magnetic chitosan chelating resin. J. Hazard. Mater. 177, 962-970.

Noh, J.S., Schwarz, J.A., 1990. Effect of $\mathrm{HNO}_{3}$ treatment on the surface-acidity of activated carbons. Carbon 28, 675-682.

Oliveira, A.B.M., Coelho, L.O., Gomes, S.S., Costa, I., Fonseca, M., de Sousa, K., Espínola, J.P., da Silva Filho, E., 2013. Brazilian palygorskite as adsorbent for metal ions from aqueous solution-kinetic and equilibrium studies. Water Air Soil Pollut. 224, 1-13.

Pavia, D., Lampman, G., Kriz, G., Vyvyan, J., 2014. Introduction to Spectroscopy. Cengage Learning.

Pearson, R.G., 1973. Hard and Soft Acids and Bases. Dowden, Hutchinson \& Ross, Stroudsburg, PA, USA.

Pośpiech, B., Walkowiak, W., 2007. Separation of copper(II), cobalt(II) and nickel(II) from chloride solutions by polymer inclusion membranes. Sep. Purif. Technol. 57, 461-465.

Ramos, S.N.C., Xavier, A.L.P., Teodoro, F.S., Elias, M.M.C., Gonçalves, F.J., Gil, L.F., Freitas, R.P., Gurgel, L.V.A., 2015. Modeling mono- and multi-component adsorption of cobalt(II), copper(II) and nickel(II), metal ions from aqueous solution onto a new carboxylated sugarcane bagasse. Part I: Batch adsorption study. Ind. Crops Prod. 74, 357-371.

Rocha, G.J.D.M., Nascimento, V.M., Gonçalves, A.R., Silva, V.F.N., Martín, C., 2015 Influence of mixed sugarcane bagasse samples evaluated by elemental and physical-chemical composition. Ind. Crops Prod. 64, 52-58. 
Ronda, A., Martín-Lara, M.A., Dionisio, E., Blázquez, G., Calero, M., 2013. Effect of lead in biosorption of copper by almond shell. J. Taiwan Inst. Chem. Eng. 44, 466-473.

Rodrigues, N.F.M., Santana, S.A.A., Bezerra, C.W.B., Silva, H.A.S., Melo, J.C.P., Vieira, A.P., Airoldi, C., Silva Filho, E.C., 2013. New chemical organic anhydride immobilization process used on banana pseudostems: a biopolymer for cation removal. Ind. Eng. Chem. Res. 52, 11007-11015.

Salman, M., Athar, M., Farooq, U., 2015. Biosorption of heavy metals from aqueous solutions using indigenous and modified lignocellulosic materials. Rev. Environ. Sci. Biotechnol. 14 (2), 211-228.

Sheoran, A.S., Sheoran, V., 2006. Heavy metal removal mechanism of acid mine drainage in wetlands: a critical review. Miner. Eng. 19, 105-116.

Smith, B.C., 1998. Infrared Spectral Interpretation: A Systematic Approach, 1st ed. CRC Press, Florida, U.S.

Srivastava, V.C., Mall, I.D., Mishra, I.M., 2006. Modelling individual and competitive adsorption of cadmium(II) and zinc(II) metal ions from aqueous solution onto bagasse fly ash. Sep. Sci. Technol. 41, 2685-2710.

Sun, R.C., 2010. Cereal Straw as a Resource for Sustainable Biomaterials and Biofuels: Chemistry, Extractives, Lignins, Hemicelluloses and Cellulose, 1st ed. Elsevier, Oxford, UK.
Silva Filho, E.C., Santos Júnior, L.S., Silva, M.M.F., Fonseca, M.G., Santana, S.A.A Airoldi, C., 2013. Surface cellulose modification with 2-aminomethylpyridine for copper, cobalt, nickel and zinc removal from aqueous solution. Mater. Res. $16,79-84$.

Ünlü, N., Ersoz, M., 2006. Adsorption characteristics of heavy metal ions onto a low cost biopolymeric sorbent from aqueous solutions. J. Hazard. Mater. 136 272-280.

Vieira, R.S., Beppu, M.M., 2006. Interaction of natural and crosslinked chitosan membranes with $\mathrm{Hg}(\mathrm{II})$ ions. Colloids Surf. A 279, 196-207.

Wan Ngah, W.S., Hanafiah, M.A.K.M., 2008. Removal of heavy metal ions from wastewater by chemically modified plant wastes as adsorbents: a review. Bioresour. Technol. 99, 3935-3948.

Yavuz, Ö., Altunkaynak, Y., Güzel, F., 2003. Removal of copper, nickel, cobalt and manganese from aqueous solution by kaolinite. Water Res. 37, 948-952.

Yu, H., You, Y., Lei, F., Liu, Z., Zhang, W., Jiang, J., 2015. Comparative study of alkaline hydrogen peroxide and organosolv pretreatments of sugarcane bagasse to improve the overall sugar yield. Bioresour. Technol. 187, 161-166.

Yu, Y., Zhuang, Y.-Y., Wang, Z.-H., 2001. Adsorption of water-soluble dye onto functionalized resin. J. Colloid Interface Sci. 242, 288-293. 